\title{
Características da Atmosfera na Primavera Austral Durante o El Niño de 2015/2016
}

\author{
Heloisa Ramos Pereira ${ }^{1,2}$, Michelle Simões Reboita ${ }^{2}$, Tércio Ambrizzi ${ }^{3}$ \\ ${ }^{1}$ Instituto Agronômico de Campinas, Campinas, SP, Brasil. \\ ${ }^{2}$ Instituto de Recursos Naturais, Universidade Federal de Itajubá, MG, Brasil. \\ ${ }^{3}$ Departamento de Ciências Atmosféricas Universidade de São Paulo, São Paulo, SP, Brasil.
}

Recebido em 17 de Julho de 2016 - Aceito em 16 de Março de 2017

\begin{abstract}
Resumo
O El Niño (EN) é caracterizado pelo aquecimento anômalo das águas superficiais do oceano Pacífico Tropical central e leste que afeta o clima global e regional através das anomalias da circulação da atmosfera. O EN 2015/2016 foi classificado como um evento muito forte. Portanto, esse estudo tem como objetivo mostrar as características da atmosfera durante a ocorrência desse evento nos meses de setembro, outubro e novembro de 2015. Entre os resultados, têm-se o deslocamento para leste da célula de circulação zonal de Walker, intensificação dos jatos subtropical e polar, presença de anomalias positivas de altura geopotencial no oceano Pacífico próximas ao sul da América do Sul e anomalias negativas no sudeste desse continente e no oceano Atlântico. Além disso, há maior frequência de ciclones nas latitudes subtropicais do oceano Atlântico e convergência do fluxo de umidade integrado na vertical sobre o sudeste da América do Sul. Essas características contribuem para anomalias de precipitação e temperatura do ar na América do Sul. Palavras-chave: El Niño, correntes de jato, precipitação, Hemisfério Sul.
\end{abstract}

\section{Characteristics of the Atmosphere in the Austral Spring During the El Niño 2015/2016}

\begin{abstract}
The El Niño (EN) is characterized by an anomalous warming of the central and eastern surface of the Tropical Pacific Ocean waters, which affects global and regional climate through the circulation anomalies in the atmosphere. The EN $2015 / 2016$ was classified as very strong. Therefore, this study aims to show the atmospheric characteristics during the occurrence of this event in September, October and November of 2015. Among the results, there are the shift to eastern of the zonal Walker Cell, the intensification of the subtropical and polar jets, the presence of positive anomalies of geopotential height in the Pacific ocean near the southern of South America and negative anomalies in the south and southeast of the continent and the Atlantic ocean. Moreover, there is an increase of the cyclone frequency in the subtropical latitudes of the Atlantic Ocean, and convergence of vertically integrated flux moisture on the southeastern South America. These characteristics contribute to precipitation anomalies and air temperature in South America.
\end{abstract}

Keywords: El Niño, jet streams, precipitation, Southern Hemisphere.

\section{Introdução}

O fenômeno El Niño-Oscilação Sul (ENOS) é um dos mais importantes modos de variabilidade climática do acoplamento oceano-atmosfera, pois afeta a circulação atmosférica global que, por consequência, altera a precipitação e temperatura do ar em diferentes lugares do planeta como, por exemplo, na América do Sul (Aceituno, 1988; Coelho et al., 1999; Andreoli et al., 2016). O ENOS possui uma componente oceânica, o El Niño ou a La Niña, e uma componente atmosférica, a Oscilação Sul. O El Niño (EN) corresponde ao aquecimento anômalo da temperatura da superfície do mar (TSM) no oceano Pacífico Tropical central e leste, incluindo as vizinhanças da costa oeste da América do Sul (AS). Já, a La Niña corresponde ao resfriamento anômalo da TSM no oceano Pacífico Tropical central e leste (Philander, 1985). Para monitorar a evolução das

Autor de correspondência: Heloisa Ramos Pereira, heloisaramos92@gmail.com. 
anomalias de TSM no oceano Pacífico Tropical, a National Oceanic and Atmospheric Administration (NOAA) utiliza quatro regiões (Fig. 1f) denominadas de Niño 1+2, 3, 3.4 e 4 (https:/www.ncdc.noaa.gov/teleconnections/enso/indicators/sst.php). Além disso, na região de Niño 3.4, há um índice para acompanhamento das anomalias de TSM chamado de Oceanic Niño Index (ONI). A componente atmosférica do ENOS, a Oscilação Sul, corresponde a flutuações na pressão atmosférica ao nível médio do mar entre a alta subtropical do Pacífico sudeste e a baixa pressão no norte-nordeste da Austrália. A Oscilação Sul também é monitorada através de um índice (Índice de Oscilação Sul IOS) computado com base na diferença de pressão atmosférica entre as localidades de Darwin (12²0' S, 130 $52^{\prime}$ E) e Taiti $\left(17^{\circ} 33^{\prime}\right.$ S, $\left.149^{\circ} 31^{\prime} \mathrm{W}\right)$. Quando há anomalias positivas de TSM no Pacífico Tropical central e leste, a pressão atmosférica no Taiti torna-se menor do que em Darwin de forma que o IOS é negativo. Já quando há anomalias negativas de TSM no Oceano Pacifico tropical central e leste, a pressão em Taiti é maior do que em Darwin, sendo o IOS positivo. Portanto, quando há El Niño (anomalias positivas de TSM), o IOS é negativo, e quando há La Niña (anomalias negativas de TSM), o IOS é positivo.

Em episódios de EN, a termoclina próxima à costa oeste da AS se torna mais rasa e há redução da ressurgência oceânica (Trenberth, 2013), o que diminui o transporte de nutrientes para os peixes e demais animais marinhos, causando impactos negativos na atividade pesqueira. Durante os eventos de EN, uma das primeiras modificações na circulação atmosférica é o enfraquecimento dos ventos alísios sobre o oceano Pacífico (Trenberth, 2013). Isso permite que a convecção tropical, antes confinada no Pacífico Tropical oeste, se desenvolva ao longo do Pacífico Tropical central e leste que, por consequência, altera as células de circulação zonal de Walker.

Com as anomalias positivas de TSM no Pacífico Tropical central e leste em episódios de EN, os fluxos de calor latente e sensível do oceano para a atmosfera se intensificam (Philander, 1990; Trenberth, 2013). Com isso, a convecção é favorecida e a temperatura da média troposfera tropical pode ser $1{ }^{\circ} \mathrm{C}$ mais elevada do que em casos de LN (Horel e Wallace, 1981; Barnett, 1985). A baixa atmosfera também se torna mais quente em anos de EN devido à transferência de calor sensível do mar para o ar (Trenberth, 2013) e, desta forma, o gradiente horizontal de temperatura trópicos-extratrópicos aumenta, contribuindo para intensificar a corrente de jato subtropical. Bjerknes (1966) também menciona que a intensificação do jato subtropical está associada à intensificação da circulação de Hadley em eventos EN, que produz aumento do transporte de momento angular em direção aos polos na alta troposfera. $\mathrm{O}$ aumento da intensidade do jato subtropical em episódios de EN é documentado em vários estudos como em Chen et al. (1996), Grimm et al. (1998), Coelho (2001) e Magaña e Ambrizzi (2005). Segundo Ambrizzi e Hoskins (1997), as correntes de jato são o caminho preferencial para as ondas de Rossby ou, em outras palavras, são guias de ondas. Tanto as correntes de jato quanto essas ondas influenciam a ocorrência de ciclones em superfície. Portanto, em anos de EN é de se esperar mudanças no padrão das ciclogêneses no globo. Com relação ao Hemisfério Sul, Reboita et al. (2014) verificaram que não há diferença significativa no número de ciclogêneses em anos de $\mathrm{EN}$, neutros e de LN, mas existe uma mudança na região preferencial de ocorrência destes sistemas. Em anos de EN, há aumento da ocorrência de ciclones entre $30^{\circ}$ e $60^{\circ} \mathrm{S}$ (o que inclui as latitudes de atuação do jato subtropical) e decréscimo entre $60^{\circ}$ e $70^{\circ} \mathrm{S}$. Num estudo mais regional, Silva e Ambrizzi (2010) mostraram que em anos de EN fortes há um ligeiro aumento na densidade de ciclones extratropicais sobre o sudeste da AS (mas não sobre o oceano adjacente) e que a pressão central desses sistemas é mais profunda do que nos demais anos. Esses autores ainda mencionam que em eventos de EN fortes há um padrão de trem de ondas em $200 \mathrm{hPa}$ com um centro ciclônico sobre os trópicos e um anticiclônico sobre o leste do sudeste da AS. Nessa última região citada, o centro anticiclônico pode contribuir para o desenvolvimento de movimento vertical ascendente em $500 \mathrm{hPa}$. Em baixos níveis, isso favorece o deslocamento e intensificação do jato de baixos níveis a leste dos Andes da região tropical para o sudeste da AS. Como o jato de baixos níveis transporta umidade, a maior disponibilidade dessa sobre o sudeste da AS pode contribuir para a ocorrência de ciclones mais intensos bem como para uma maior frequência desses sistemas.

Em episódios de EN, as células de circulação zonal de Walker também são afetadas (Ambrizzi et al., 2004). Lau et al. (2003) e Grimm e Ambrizzi (2009) mostram que os movimentos ascendentes de $120^{\circ} \mathrm{E}$ a $180^{\circ}$ deslocam-se para $180^{\circ}$ e $120^{\circ} \mathrm{W}$ e que um ramo subsidente dessa célula enfraquece o ramo ascendente que ocorre sobre a Amazônia. Portanto, na Amazônia o enfraquecimento da atividade convectiva pode levar a déficits de precipitação. Já sobre o nordeste do Brasil e Atlântico tropical, tal ramo subsidente contribui para intensificar os movimentos descentes e para tornar a atmosfera mais seca nessa região. Kousky et al. (1984) já haviam relatado que durante o verão de eventos EN há um ramo de correntes descendentes próximo à costa da região nordeste do Brasil, fato que inibe a precipitação na costa nordestina. No sul do Brasil e sudeste da AS, os eventos de EN contribuem para anomalias positivas de precipitação (Ropelewski e Halpert, 1987; Rao e Hada, 1990; Grimm et al., 1997, 1998; Reboita e Santos, 2014). A maioria dessas anomalias positivas está relacionada a circulações quase-estacionárias, tais como o padrão Pacífico/América do Sul (PSA), decorrentes da fonte de calor anômala sobre o Pacífico Tropical (Mo e White, 1985; MO, 2000; Mo e Nogués-Peagle, 2001). Coelho (2001), através de uma análise ray tracing, menciona que durante os eventos de EN há um caminho preferencial para a propagação 
das ondas quase-estacionárias partindo da região tropical, ao sul da convecção anômala no Pacífico central, em direção ao sudeste, seguindo uma trajetória curva que ao atingir latitudes entre $30^{\circ} \mathrm{S}$ e $50^{\circ} \mathrm{S}$ é desviada em direção ao norte, podendo atingir a região tropical da AS. Já Vera et al. (2004) mencionam que esse padrão de ondas em eventos de EN é muito evidente nas anomalias de circulação do Hemisfério Sul durante o inverno e mais amplificado durante a primavera. Grimm et al. (1998) também mostram que as anomalias positivas de precipitação sobre o sudeste da AS são muito consistentes durante a primavera austral.

Com relação às ondas quase-estacionárias relacionadas ao PSA, Coelho (2001) verificou que há uma alternância entre anomalias ciclônicas e anticiclônicas que implicam na determinação dos padrões de precipitação nos subtrópicos da AS. Por exemplo, em anos de EN, na baixa troposfera existe um núcleo anômalo de circulação ciclônica na região subtropical, centrado em $25^{\circ} \mathrm{S}$ e $70^{\circ} \mathrm{W}$, sobre o norte da Argentina e parte da região sul do Brasil. Já, sobre o Atlântico Sul tem-se a circulação anticiclônica da alta subtropical. Na presença desses centros de pressão, há a configuração de dois jatos de baixos níveis, um jato de leste na região equatorial, e outro jato a leste dos Andes, que possui trajetória meridional. Grande parte da precipitação no sudeste da AS nos eventos de EN está associada ao jato de baixos níveis a leste dos Andes que transporta calor e umidade da Amazônia para os subtrópicos da AS. Silva et al. (2006) mostraram que em eventos EN o jato possui intensidade máxima sobre o norte da Argentina, Paraguai e sul do Brasil e, em eventos de LN, a máxima intensidade do jato fica deslocada ligeiramente para norte. Já Silva et al. (2009), estudando o verão austral, identificaram uma preferência para a ocorrência de maior (menor) número de jatos de baixos níveis em anos de EN (LN). Com base no exposto, pode-se formular o seguinte modelo conceitual: a região de circulação anômala ciclônica nos subtrópicos da AS atua a fim de contribuir para um gradiente de pressão entre ela e a Amazônia de forma a favorecer a ocorrência de jatos de baixos níveis a leste dos Andes. Esses jatos transportam calor e umidade que ao encontrarem a região de baixa pressão anômala favorecem a convecção e a precipitação. Portanto, esta é uma possível explicação para chuvas acima do total climatológico no sul do Brasil em eventos de EN.

A distribuição espacial das anomalias de precipitação durante os eventos EN não são sempre iguais. A configuração dessas anomalias depende da intensidade (Coelho et al., 1999) e da localização das anomalias de TSM no Pacífico Tropical (Ashok et al., 2007; Andreoli et al., 2016). Ressalta-se que os estudos previamente citados não fazem distinção nos impactos causados na AS pelas diferentes configurações espaciais das anomalias de TSM no Pacífico Tropical. Estudos com essa finalidade surgiram no final da década de 2000 como será mostrado na sequência.

Ashok et al. (2007), através da técnica de funções ortogonais empíricas (FOE), verificaram que o segundo modo das FOE (obtido com dados mensais de TSM) apresenta um aquecimento na parte central do Pacífico Tropical cercado em ambos os lados por águas mais frias. Os autores denominaram esse padrão de El Niño Modoki. Esse tipo de EN também tem sido denominado de Pacífico-Central (PC), enquanto que o EN clássico (canônico) é denominado de Pacífico-Leste (PL). Yu e Kim (2013) classificam um EN como clássico quando esse se origina no Pacífico Tropical leste próximo da região de Niño 1+2; e o El Niño Modoki quando se origina no Pacífico Tropical central próximo da região de Niño 4. Esses dois tipos de El Niño podem ser dirigidos por diferentes mecanismos, mas podem ocorrer ao mesmo tempo. Quando isso ocorre, Yu e Kim (2013) definiram a existência de um terceiro tipo de EN, chamado de MIX. Com base nos diferentes tipos de EN, Capotondi et al. (2015) introduziram a ideia de diversidade de EN bem como a existência de um continuum (diferentes padrões espaciais de anomalias de TSM associadas ao EN).

Uma vez que o acoplamento oceano-atmosfera e os padrões de circulação desenvolvidos dependem do tipo de EN (isto é, da configuração espacial das anomalias de TSM sobre o oceano Pacífico Tropical), estudos têm apresentado o impacto desses na precipitação da AS (Li et al., 2011; Tedeschi et al., 2013, 2015; Andreoli et al., 2016). Li et al. (2011) analisaram os impactos do EN clássico e do Modoki na precipitação da Amazônia. Por exemplo, no inverno e primavera austral, enquanto o EN clássico contribui para déficit de precipitação, o Modoki contribui para precipitação acima da média climatológica. Já Andreoli et al. (2016) estudaram o impacto dos três tipos de EN na precipitação da AS. Inicialmente, os autores identificaram os casos de EN com base no ONI. Após, usando a metodologia de Yu e Kim (2013), separam os casos de EN nos três tipos: PL, PC e MIX. Com essa metodologia, EN fortes como o de 1982/1983 e 1997/1998 foram classificados como PL, o de 2002/2003 como PC e o de 1986/1987 como MIX, por exemplo. Andreoli et al. (2016) mencionam que os diferentes padrões de anomalias de TSM afetam tanto a circulação de grande escala (circulação de Walker e trem de ondas de Rossby) quanto à circulação local (jato de baixos níveis a leste dos Andes) ocasionando anomalias de precipitação distintas sobre a AS. O padrão do trem de ondas de Rossby depende do tipo de EN e da estação do ano. Em todas as estações do ano, o jato de baixos níveis a leste dos Andes é mais intenso durante eventos de EN clássico, enquanto é mais fraco ou inexistente na ocorrência dos outros dois tipos de EN. Embora Andreoli et al. (2016) tenham descrito os padrões de anomalias na precipitação para os períodos JJA, SON, DJF e MAM, neste trabalho só serão mencionadas as anomalias do período SON. O EN PC em SON causa anomalias positivas de precipitação no sudeste da AS e anomalias negativas entre o leste da Amazônia e nordeste do Brasil, entretanto, essas anomalias cobrem uma menor área do que nos outros dois tipos de EN. 
No EN PL também ocorrem intensas anomalias positivas de precipitação no sudeste da AS em SON, mas nesse período as anomalias negativas significativas se concentram no extremo norte da AS. Por fim, no EN MIX, em SON há anomalias positivas de precipitação no sudeste da AS que se estendem pelo leste do Brasil até aparecerem as anomalias negativas que se estendem do norte de Minas Gerais e Bahia para o norte da AS. Embora o padrão espacial das anomalias de precipitação do evento tipo MIX se assemelham com a do tipo PL, no tipo MIX a intensidade das anomalias positivas é menor. Os efeitos dos diferentes tipos de EN em outros locais do globo podem ser encontrados, por exemplo, em Taschetto et al. (2009) e Capotondi et al. (2015).

Também é interessante ressaltar que outros mecanismos de teleconexão de baixa frequência podem se acoplar ao ENOS e contribuir para sua intensificação ou enfraquecimento. Um exemplo é a Oscilação Decadal do Pacífico (ODP). A ODP é caracterizada por anomalias de sinais opostos (TSM, pressão atmosférica etc.) entre o Pacífico Tropical e o Pacífico Norte, sendo que nesse último as anomalias são mais expressivas (Mantua et al., 1997). Duas características diferenciam a ODP do fenômeno ENSO (EN e LN). Primeiro, os eventos da ODP no século XX duraram de 20 a 30 anos enquanto os episódios de ENSO tendem a apresentar duração de 6 a 18 meses. Segundo, os sinais da ODP são mais visíveis no Pacífico Norte com traços residuais no Pacífico Tropical enquanto no fenômeno ENSO ocorre o oposto. Mesmo com essas características a ODP pode influenciar o ENOS, pois a ocorrência concomitante de EN e fase positiva da ODP pode intensificar as anomalias positivas de TSM no Pacífico Tropical e fortalecer o EN (enfraquecer a LN). Já na ocorrência de fase negativa pode enfraquecer o EN (intensificar a LN). Silva et al. (2010) estudaram os efeitos do acoplamento do EN com as fases positivas e negativas da ODP na precipitação da AS durante o verão austral. Na ocorrência de EN e fase positiva da ODP, há mais precipitação sobre o sudeste da AS do que na ocorrência de EN e fase negativa da ODP. Com relação ao impacto nos ciclones extratropicais, foi verificada maior densidade desses sistemas sobre o sudeste da AS (mas não no oceano adjacente) na ocorrência de EN e fase positiva da ODP do que na fase negativa da ODP.

Como o conhecimento das anomalias da circulação atmosférica durante eventos EN é de grande relevância para compreender os impactos na precipitação, o presente estudo tem como objetivo descrever as características da circulação atmosférica no Hemisférico Sul, com enfoque na AS, durante os meses de setembro a novembro de 2015 quando foi registrado um EN muito forte, segundo o ONI (http://ggweather.com/enso/oni.htm). A primavera austral foi escolhida por ser a estação do ano em que o PSA é bastante evidente (Vera et al., 2004) e que há anomalias positivas de precipitação significativas no sudeste da AS (Grimm et al., 1998b, 2000) quando da ocorrência de EN.
Além disso, o EN ocorrido será classificado num dos três tipos: PL, PC ou MIX.

\section{Materiais e Métodos}

Para analisar as anomalias da circulação atmosférica associadas com o evento EN na primavera austral de 2015 foram utilizados dados médios mensais da reanálise ERAInterim (Dee et al., 2011). Todas as variáveis atmosféricas utilizadas são descritas na Tabela $1 \mathrm{e}$ foram obtidas para o período de 1980 a 2015. Para computar as anomalias das variáveis, foi inicialmente calculada a média climatológica do trimestre setembro a novembro de 1980 a 2015. Na sequência, computou-se média do mesmo trimestre somente para 2015. Por fim, a diferença entre a média de 2015 e a de longo período foi calculada. A Tabela 1 também apresenta a fonte dos índices de TSM e da ODP utilizados no estudo. Com os índices de TSM será possível definir o tipo de EN (detalhes na seção 3.1).

A partir das variáveis básicas foram obtidas variáveis secundárias. $\mathrm{O}$ vetor gradiente horizontal de temperatura do ar, que fornece a direção e sentido do maior crescimento dessa variável, foi calculado através da Eq. (1).

$$
\vec{\nabla} T=\frac{\partial T}{\partial x} \vec{i}+\frac{\partial T}{\partial y} \vec{j}
$$

onde $T$ é a temperatura do $\operatorname{ar}\left({ }^{\circ} \mathrm{C}\right)$ e $x$ e $y$ indicam as direções leste-oeste e norte-sul, respectivamente.

A divergência do fluxo de umidade integrado na vertical foi calculada através da Eq. (2):

$$
\vec{\nabla} \cdot \vec{Q}=\frac{1}{g}\left[\frac{\partial}{\partial x}\left(\int_{p_{t}}^{p_{s}} q u d p\right)+\frac{\partial}{\partial y}\left(\int_{p_{t}}^{p_{s}} q v d p\right)\right]
$$

onde $g$ representa a aceleração da gravidade $\left(9,8 \mathrm{~ms}^{-2}\right), q$ é a umidade específica em unidades de $\mathrm{g} / \mathrm{kg}, p_{s}$ representa a pressão atmosférica em $1000 \mathrm{hPa}$ e $p_{t}$ a pressão atmosférica em $100 \mathrm{hPa}$. Os produtos $q u$ e $q v$ indicam o transporte horizontal de umidade pelo vento zonal e meridional, respectivamente. Os valores negativos (positivos) obtidos na Eq. (2) indicam convergência (divergência) de umidade. Deve ser mencionado que as Eqs. (1) e (2) foram apresentadas em coordenadas cartesianas, porém no cálculo dessas no software GrADS é levado em consideração a esfericidade da Terra.

Para representar o perfil vertical da variável ômega (velocidade vertical) e componente zonal, calculou-se a média simples dessas variáveis, em pontos de grade, entre $5^{\circ} \mathrm{S}$ a $5^{\circ} \mathrm{N}$. Para facilitar a representação dos resultados em forma de vetores, a variável ômega foi multiplicada por -100 .

Também são apresentadas figuras com a anomalia da densidade da trajetória dos ciclones no Hemisfério Sul nos meses de setembro a novembro de 2015. Além disso, são mostradas a anomalia sazonal da trajetória e da pressão central dos ciclones na primavera. Nessa parte do estudo 
são utilizados dados de pressão ao nível médio do mar da reanálise 1 do NCEP (Kalnay et al., 1996) e a climatologia dos ciclones inclui os anos de 1980 a 2012. Detalhes do algoritmo de identificação dos sistemas e do cálculo da densidade são apresentados em Reboita et al. (2014). Os mapas da densidade mensal de ciclones utilizados nesse estudo também estão disponíveis no sítio www.grec.iag.usp.br.

A fim de comparar a precipitação do evento EN de SON/2015 com outros eventos ocorridos entre 1980 a 2014, selecionaram-se apenas os eventos clássicos (Andreoli et al., 2016): o de 1982 e 1997. Já para analisar a intensidade dos jatos de altos níveis também se incluíram os eventos de 1987 (MIX) e 2002 (Modoki).

\section{Resultados}

\subsection{Descrição das anomalias de TSM no Oceano Pacífico Tropical}

O ONI é um índice que computa a média móvel de três meses das anomalias de TSM na região de Niño 3.4 $\left(5^{\circ} \mathrm{N}-5^{\circ} \mathrm{S}, 120^{\circ}-170^{\circ} \mathrm{W}\right)$. Quando cinco valores consecutivos, obtidos com a média móvel, forem iguais ou acima (abaixo) de 0,5 (-0,5) há ocorrência de EN (LN). Segundo o

Tabela 1 - Dados utilizados no estudo.

\begin{tabular}{|c|c|c|c|c|}
\hline Dados & Resolução espacial & Área de estudo & Período & Fonte \\
\hline $\begin{array}{l}\text { Vento Zonal } \\
(1000-100 \mathrm{hPa})\end{array}$ & $1,5^{\circ} \times 1,5^{\circ}$ & Global: $\left(0^{\circ}-360^{\circ} \mathrm{E}, 0^{\circ}-180^{\circ} \mathrm{N}\right)$ & $\begin{array}{l}\text { Usado no estudo: setembro, ou- } \\
\text { tubro e novembro de } 1980 \text { a } \\
2015 \text { (usado no estudo) }\end{array}$ & $\begin{array}{l}\text { Reanálise ERA-Interim Dee } e t \\
\text { al. }(2011) \\
\text { http://apps.ecmwf.int/datasets/dat } \\
\text { a/interim-full-moda/levtype }=\mathrm{sfc} /\end{array}$ \\
\hline $\begin{array}{l}\text { Vento Meridional } \\
(1000-100 \mathrm{hPa})\end{array}$ & $1,5^{\circ} \times 1,5^{\circ}$ & Global: $\left(0^{\circ}-360^{\circ} \mathrm{E}, 0^{\circ}-180^{\circ} \mathrm{N}\right)$ & $\begin{array}{l}\text { Usado no estudo: setembro, ou- } \\
\text { tubro e novembro de } 1980 \text { a } \\
2015 \text { (usado no estudo) }\end{array}$ & $\begin{array}{l}\text { Reanálise ERA-Interim Dee et } \\
\text { al. (2011) }\end{array}$ \\
\hline $\begin{array}{l}\text { Velocidade Vertical } \\
\text { (Ômega) (1000-100 hPa) }\end{array}$ & $1,5^{\circ} \times 1,5^{\circ}$ & Global: $\left(0^{\circ}-360^{\circ} \mathrm{E}, 0^{\circ}-180^{\circ} \mathrm{N}\right)$ & $\begin{array}{l}\text { Usado no estudo: setembro, ou- } \\
\text { tubro e novembro de } 1980 \text { a } \\
2015 \text { (usado no estudo) }\end{array}$ & $\begin{array}{l}\text { Reanálise ERA-Interim Dee et } \\
\text { al. (2011) }\end{array}$ \\
\hline $\begin{array}{l}\text { Umidade Específica } \\
(1000-100 \mathrm{hPa})\end{array}$ & $1,5^{\circ} \times 1,5^{\circ}$ & Global: $\left(0^{\circ}-360^{\circ} \mathrm{E}, 0^{\circ}-180^{\circ} \mathrm{N}\right)$ & $\begin{array}{l}\text { Usado no estudo: setembro, ou- } \\
\text { tubro e novembro de } 1980 \text { a } \\
2015 \text { (usado no estudo) }\end{array}$ & $\begin{array}{l}\text { Reanálise ERA-Interim Dee et } \\
\text { al. (2011) }\end{array}$ \\
\hline $\begin{array}{l}\text { Altura Geopotencial } \\
(300,500 \text { e } 850 \mathrm{hPa})\end{array}$ & $1,5^{\circ} \times 1,5^{\circ}$ & Global: $\left(0^{\circ}-360^{\circ} \mathrm{E}, 0^{\circ}-180^{\circ} \mathrm{N}\right)$ & $\begin{array}{l}\text { Usado no estudo: setembro, ou- } \\
\text { tubro e novembro de } 1980 \text { a } \\
2015 \text { (usado no estudo) }\end{array}$ & $\begin{array}{l}\text { Reanálise ERA-Interim Dee } e t \\
\text { al. (2011) }\end{array}$ \\
\hline $\begin{array}{l}\text { Temperatura da } \\
\text { superfície do mar (TSM) }\end{array}$ & $1,5^{\circ} \times 1,5^{\circ}$ & Global: $\left(0^{\circ}-360^{\circ} \mathrm{E}, 0^{\circ}-180^{\circ} \mathrm{N}\right)$ & $\begin{array}{l}\text { Usado no estudo: setembro, ou- } \\
\text { tubro e novembro de } 1980 \text { a } \\
2015 \text { (usado no estudo) }\end{array}$ & $\begin{array}{l}\text { Reanálise ERA-Interim Dee et } \\
\text { al. (2011) }\end{array}$ \\
\hline $\begin{array}{l}\text { Pressão ao nível médio } \\
\text { do mar (PNMM, hPa) }\end{array}$ & $2,5^{\circ} \times 2,5^{\circ}$ & Global: $\left(0^{\circ}-360^{\circ} \mathrm{E}, 0^{\circ}-180^{\circ} \mathrm{N}\right)$ & $\begin{array}{l}\text { Usado no estudo: setembro, ou- } \\
\text { tubro e novembro de } 1980 \text { a } \\
2012 \text { e } 2015\end{array}$ & $\begin{array}{l}\text { Reanálise } 1 \text { do NCEP-NCAR } \\
\text { Kalnay et al. }\end{array}$ \\
\hline Precipitação & $2,5^{\circ} \times 2,5^{\circ}$ & Global: $\left(0^{\circ}-360^{\circ} \mathrm{E}, 0^{\circ}-180^{\circ} \mathrm{N}\right)$ & $\begin{array}{l}\text { Disponível de 1979-presente. } \\
\text { Usado no estudo: } 1980-2015\end{array}$ & $\begin{array}{l}\text { Global Precipitation Climatol- } \\
\text { ogy Project (GPCP)Adler et al. } \\
\text { (2003) } \\
\text { http://www.esrl.noaa.gov/psd/da } \\
\text { ta/gridded/data.gpcp.html }\end{array}$ \\
\hline $\begin{array}{l}\text { Oceanic Niño Index } \\
\text { (ONI) (usa TSM } \\
\text { ERSSTv4) }\end{array}$ & & $\begin{array}{l}\text { Região El Niño } 3.4 \\
\left(5^{\circ} \mathrm{N}-5^{\circ} \mathrm{S}, 120^{\circ}-170^{\circ} \mathrm{W}\right)\end{array}$ & $\begin{array}{l}\text { Disponível de 1950-presente. } \\
\text { Climatologia de } 1981 \text { a } 2010\end{array}$ & $\begin{array}{l}\text { Climate Prediction Center } \\
\text { (CPC) Natinal Weather } \\
\text { Servicehttp://www.cpc.ncep.noa } \\
\text { a.gov/products/analysis_moni- } \\
\text { toring/ensostuff/ensoyears.shtml }\end{array}$ \\
\hline $\begin{array}{l}\text { Anomalias de TSM nas } \\
\text { regiões de Niño } 1+2, \text { Ni- } \\
\text { ño 3, Niño } 3.4 \text { e Niño } 4 \\
\text { (usa TSM ERSSTv4) }\end{array}$ & & & $\begin{array}{l}\text { Disponível de 1950-presente. } \\
\text { Climatologia de } 1981 \text { a } 2010\end{array}$ & $\begin{array}{l}\text { http://www.cpc.ncep.noaa.gov/d } \\
\text { ata/indi- } \\
\text { ces/ersst4.nino.mth.81-10.ascii }\end{array}$ \\
\hline $\begin{array}{l}\text { Definição de ENSO fra- } \\
\text { co, moderado, forte e } \\
\text { muito forte (baseado no } \\
\text { ONI) }\end{array}$ & & $\begin{array}{l}\text { Região El Niño } 3.4 \\
\left(5^{\circ} \mathrm{N}-5^{\circ} \mathrm{S}, 120^{\circ}-70^{\circ} \mathrm{W}\right)\end{array}$ & Disponível de 1950-presente & $\begin{array}{l}\text { http://ggweather.com/enso/oni.h } \\
\text { tm }\end{array}$ \\
\hline $\begin{array}{l}\text { Índice da Oscilação De- } \\
\text { cadal do Pacífico (usa } \\
\text { TSM ERSSTv4) }\end{array}$ & & & Disponível de 1854-presente & $\begin{array}{l}\text { https://www.ncdc.noaa.gov/telec } \\
\text { onnections/pdo }\end{array}$ \\
\hline
\end{tabular}


ONI, o fenômeno EN teve início no verão austral de 2015 e se estendeu até o outono de 2016. Os índices mais elevados (iguais ou superiores a $2,0{ }^{\circ} \mathrm{C}$ ) foram registrados entre outubro de 2015 e fevereiro de 2016. Considerando o ONI de setembro-outubro-novembro (SON) de 2015, este foi de $2,0^{\circ} \mathrm{C}$. Já o ONI de novembro-dezembro-janeiro (NDJ) foi o que teve maior valor, $2,3{ }^{\circ} \mathrm{C}$. De acordo com L'Heureux et al. (2016), o EN 2015/2016 está entre os eventos mais fortes ocorridos desde 1950. De fato, de acordo com a metodologia de Null (2016; http://ggweather.com/enso/oni.htm), que classifica a intensidade dos eventos ENOS obtidos com o ONI, o EN 2015/2016 foi classificado como muito forte. Nessa metodologia, EN fraco apresenta ONI entre 0,5 e $0,9{ }^{\circ} \mathrm{C}$, moderado entre 1,0 e $1,4^{\circ} \mathrm{C}$, forte entre 1,5 e $1,9^{\circ} \mathrm{C}$ e muito forte quando as anomalias de TSM são maiores ou iguais a $2{ }^{\circ} \mathrm{C}$.

Acompanhando-se a evolução mensal das anomalias de TSM, entre janeiro de 2014 a meados de 2016, nas diferentes regiões de Niño (Figs. 1g-j), verifica-se que na região de Niño 4 a sequência de anomalias positivas e acima de $0,5^{\circ} \mathrm{C}$ se inicia em outubro de 2014 . Já nas demais regiões, essa característica só ocorre a partir de abril de 2015. Além disso, a região de Niño 1+2 (próximo à costa oeste da AS) é a única que mostra anomalias negativas de TSM nos meses de janeiro e fevereiro de 2015. Portanto, pela indicação dos índices nas regiões de Niño, sugere-se que o aquecimento do Pacífico Tropical se iniciou no setor oeste e depois se acoplou ao aquecimento da parte central e leste desse oceano. Esse padrão descrito, da evolução mensal das anomalias de TSM nas regiões de Niño, difere-se do observado em eventos clássicos de EN. A Figs. 1k-n mostra as anomalias mensais de TSM entre janeiro de 1996 a meados de 1999 que descrevem o EN 1997/1998. Na ocorrência desse evento, o aquecimento do oceano Pacífico Tropical ocorreu primeiramente no setor leste, isto é, na região de Niño 1+2 em março de 1997 e depois que as águas mais quentes se expandiram para oeste, mostrando anomalias acima de $0,5{ }^{\circ} \mathrm{C}$ em maio de 1997 nas regiões de Niño 3 e 3.4 em maio de 1997 e na região de Niño 4 em julho de 1997. Portanto, no EN 1997/1998, o aquecimento do Pacífico Tropical iniciou no setor leste e evoluiu para a parte central e oeste. Em suma, a análise da evolução mensal das anomalias de TSM nas regiões de Niño indica diferenças entre os dois eventos.

Com relação ao padrão espacial das anomalias de TSM no oceano Pacífico Tropical nos trimestres MAM, JJA e SON de 2015 e DJF e MAM de 2016 (Figs. 1a-e), nota-se a presença de uma região com águas mais quentes entre $160^{\circ} \mathrm{E}$ e $160^{\circ} \mathrm{W}$ em MAM/2015 que se conecta em JJA com as anomalias que se intensificaram, nessa estação do ano, na região entre $120^{\circ} \mathrm{W}$ e $80^{\circ} \mathrm{W}$. Em SON, as anomalias positivas de TSM sobre o Pacífico Tropical se tornam mais intensas e em DFJ de 2016 se expandem na direção norte-sul. Já em MAM de 2016, as anomalias enfraquecem e se tornam negativas próximo à costa oeste da AS.
Estudos recentes como o de Andreoli et al. (2016) e Kayano et al. (2016) mostram a existência de três tipos de EN e a configuração espacial das anomalias de TSM quando da ocorrência desses. Em Kayano et al. (2016), são apresentadas as anomalias de TSM no EN 2002/2003 que é classificado como PC (ou Modoki), no EN 1997/1998 que é o tipo PL (ou clássico) e no EN 1986-1987 que é do tipo MIX. Comparando-se as anomalias desses eventos com a do EN 2015/2016, nota-se maior semelhança do evento 2015/2016 com o evento do tipo MIX. De fato, em 2015/2016 não há uma ampla região com anomalias quentes ao longo da costa oeste da AS como num evento clássico e nem as anomalias mais intensas ficam no centrooeste do Pacífico Tropical como no caso do PC. No EN 2015/2016, as anomalias mais intensas se concentram numa banda estreita ao longo do oceano Pacífico e com valores máximos entre $130^{\circ} \mathrm{W}$ e $90^{\circ} \mathrm{W}$ e que se conectam com um outro núcleo mais a oeste, próximo à AS. L'Heureux et al. (2016) também ressaltam que o EN 2015/2016 comparado aos de 1982/1983 e 1997/1998 apresentou uma maior área com águas mais quentes do que estes no setor oeste do Pacífico Tropical e com águas mais frias, no setor leste. Esses mesmos autores mencionam que a metodologia para definir tipos de EN (PL, PC e MIX) indica a ocorrência de PL e PC, portanto no meio do ENSO continuum de Capotondi et al. (2015), o que sugere a ocorrência de um evento do tipo MIX.

Com relação à ODP, entre setembro de 2014 a julho de 2016, tal oscilação apresentou fase positiva, o que pode ter contribuído de forma positiva (intensificação) no EN 2015/2016.

\subsection{Circulação atmosférica}

A TSM influência a temperatura das camadas de ar próximas à superfície marítima de forma que essas adquirem um padrão de anomalia similar ao da TSM (Fig. 2c). Com relação a AS, em SON/2015 predominaram anomalias positivas ao norte de $30^{\circ} \mathrm{S}$ e negativas ao sul dessa latitude.

Associado ao aquecimento anômalo da atmosfera tropical sobre o oceano Pacífico, o gradiente horizontal de temperatura do ar trópicos-subtrópicos se intensifica, conforme indicado no campo de anomalia dessa variável (Fig. 3). A presença de gradientes horizontais de temperatura em superfície implica em aumento do gradiente horizontal de pressão até a altitude dos jatos, o que contribui para intensificá-los. Tal intensificação pode ser obtida matematicamente com a relação do vento térmico (Holton, 2004; Stull, 2000), pois conhecendo a variação horizontal da temperatura do ar é possível estimar a variação vertical do vento geostrófico. Isso pode ser uma das razões para a maior intensidade do jato subtropical em períodos de EN no Hemisfério Sul, como mostra a Fig. 4. Além disso, também se nota um pequeno deslocamento da máxima intensidade do jato subtropical para norte, alterando assim o posicio- 
a) Anomalia TSM MAM2015-CLIM(1980/2015)

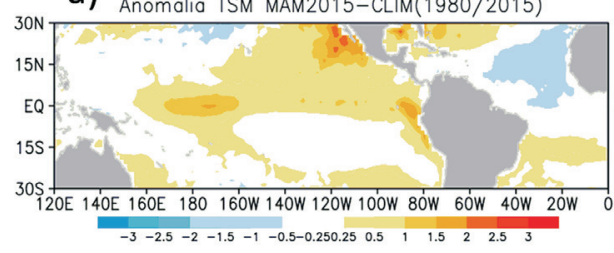

b) Anomalio TSM JJA2015-JJA(1980/2015)

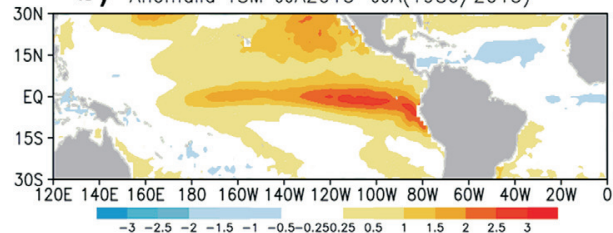

c)

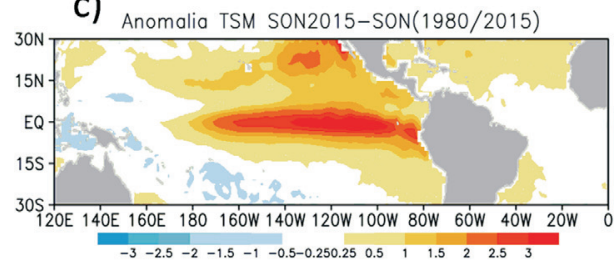

2015/2016

(g)

Niño $1+2$

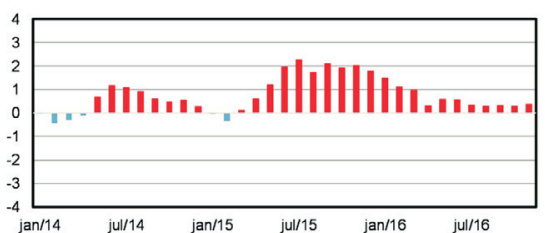

(h)

Niño 3

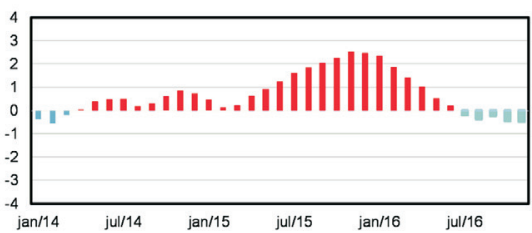

(i)

Niño 3.4

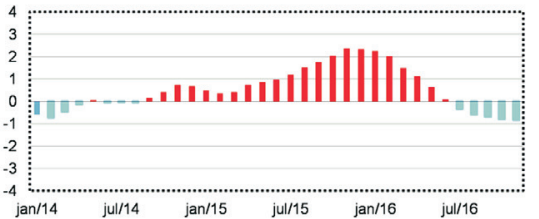

(j)

Niño 4

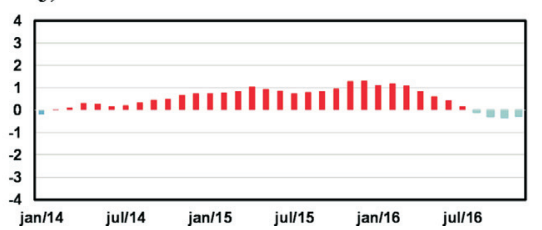

d) Anomalio TSM DJF2016-DJF(1980/2015)

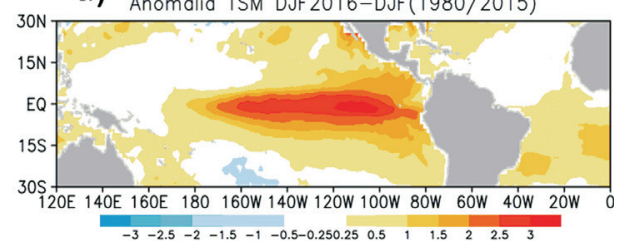

e) Anomalia TSM MAM2016-MAM(1980/2015)

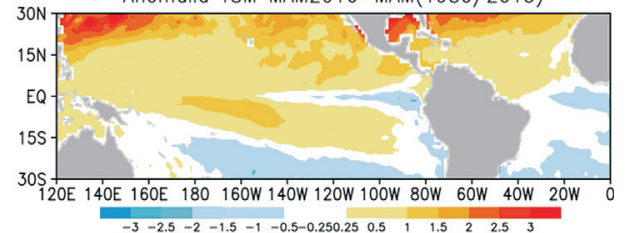

f)

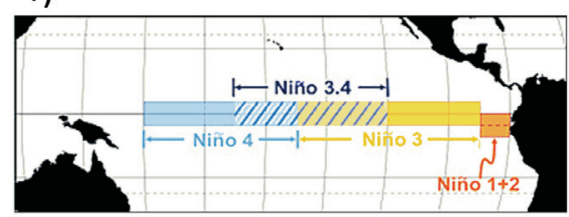

1997/1998

(k)

Niño $1+2$

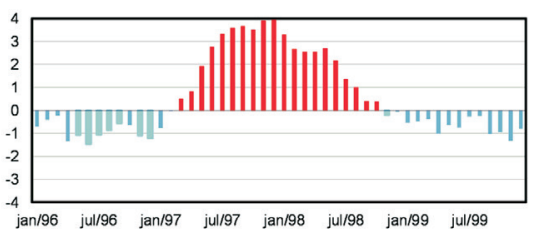

(1)

Niño 3

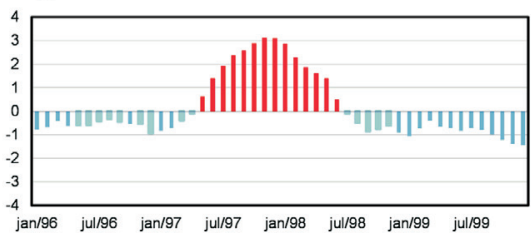

(m)

Niño 3.4

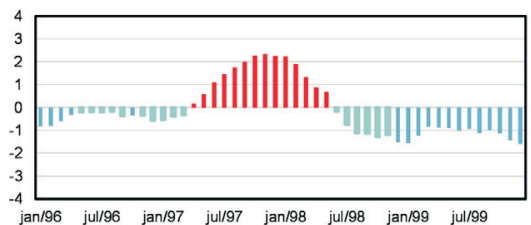

(n)

Niño 4

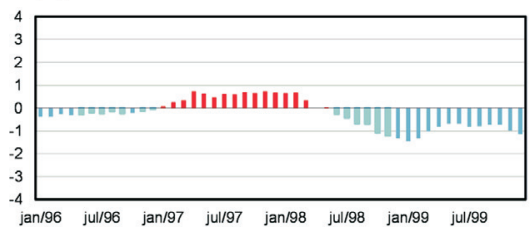

Figura 1 - (a-e) Anomalia da TSM $\left({ }^{\circ} \mathrm{C}\right)$ para os trimestres MAM/2015, JJA/2015, SON/2015, DJF/2016 e MAM/2016 baseada nos dados disponibilizados pelo ECMWF e considerando o período entre 1980 e 2015 para cálculo da climatologia; (f) localização das regiões de Niño no oceano Pacífico Tropical (fonte: http://www.srh.weather.gov/srh/jetstream/tropics/enso.html) e (g-n) evolução das anomalias de TSM nas regiões de Niño mostradas em (f) para o evento clássico de EN 1997/1998 e para o EN 2015/2016. As anomalias de TSM nas regiões de Niño foram obtidas do CPC/NOAA e a climatologia considera o período de 1981 a 2010. 
(a) Climatolgia Temperatura $2 \mathrm{~m}$ SON 1980/2015

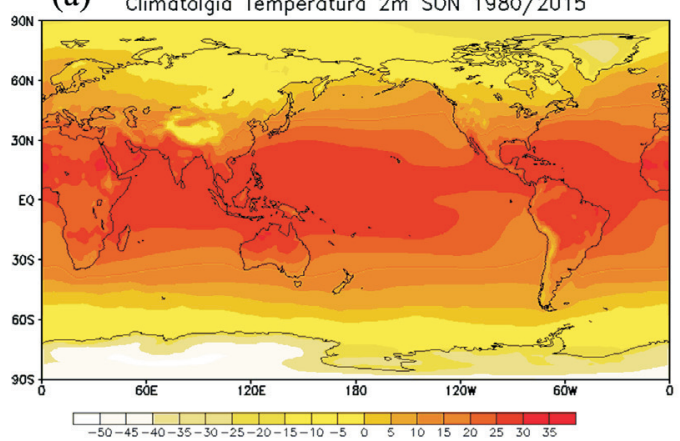

(b)

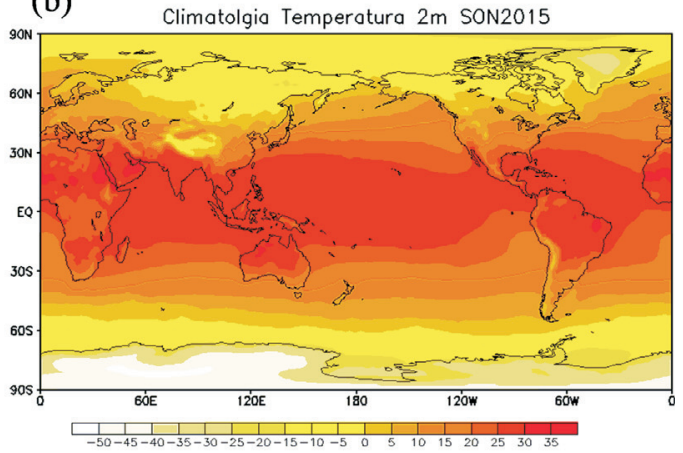

(c) Anom. Temperatura $2 m$ SON2015-SON1980/2015

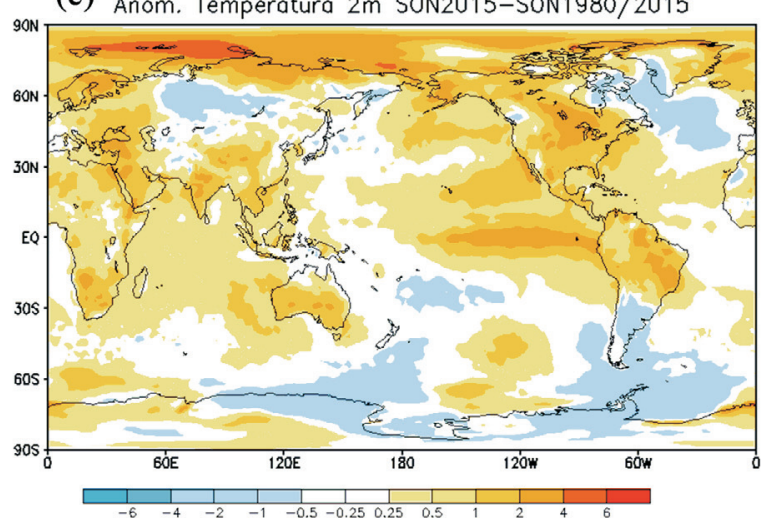

Figura 2 - Temperatura do ar a $2 \mathrm{~m}\left({ }^{\circ} \mathrm{C}\right)$ : (a) média climatológica (1980-2015) de SON, (b) média SON/2015 e (c) anomalia da temperatura do ar.

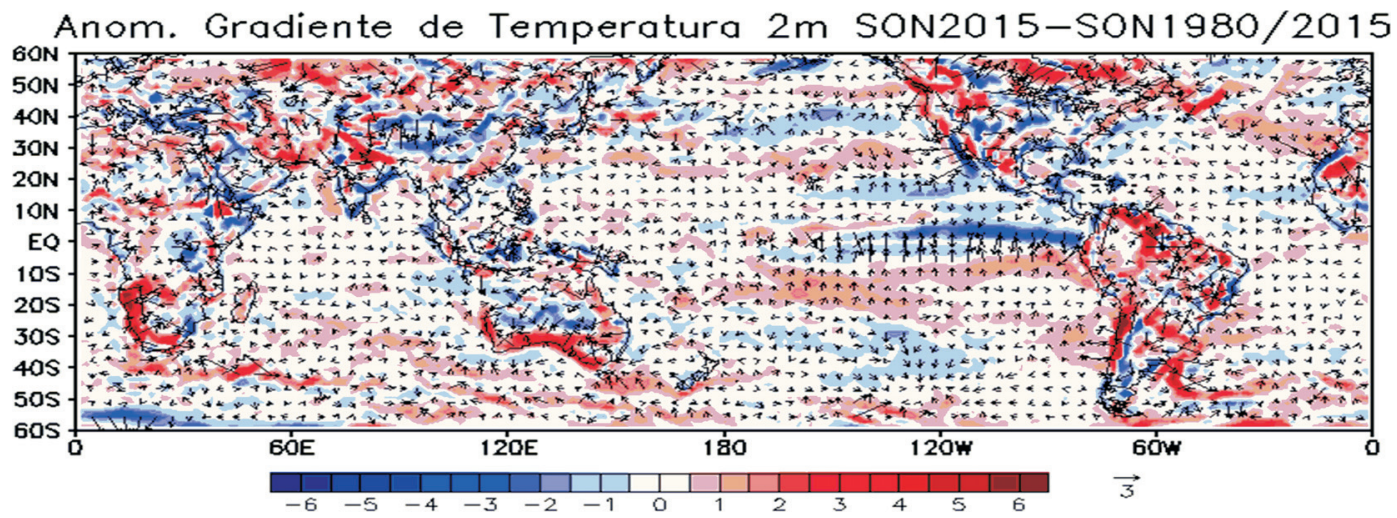

Figura 3 - Anomalia da magnitude do gradiente horizontal de temperatura do $\operatorname{ar}\left({ }^{\circ} \mathrm{C} / \mathrm{km}\right)$ a $2 \mathrm{~m}$ (cores) e vetor gradiente (setas).

namento do guia de ondas de Rossby e, portanto, influenciando a região de máxima precipitação sobre a AS, particularmente na sua parte sudeste.

Na Fig. 4 tem-se a média zonal da intensidade do vento em $300 \mathrm{hPa}$ (computada considerando todas as longitudes do globo) durante os eventos EN de 1982, 1997 e 2015 e na climatologia (1980 a 2015). Durante os episódios de EN, o vento zonal no Hemisfério Sul apresenta intensidade acima da média climatológica nas latitudes próximas a $30^{\circ} \mathrm{S}$ e $60^{\circ} \mathrm{S}$, ou seja, nas regiões dos jatos em altos níveis subtropical e polar, respectivamente. Além disso, as máximas intensidades do jato subtropical estão ligeiramente a norte do que na climatologia. Resultados similares foram obtidos por Magaña e Ambrizzi (2005) durante eventos de EN ocorridos no verão austral dos anos de 1982/1983, 1986/1987 e 1991/1992. Nas latitudes de $30^{\circ} \mathrm{S}$ e $60^{\circ} \mathrm{S}$, a diferença na intensidade do vento em relação à climatologia é de, aproximadamente, $3 \mathrm{~m} / \mathrm{s}$. Portanto, fica claro que o EN influencia diretamente tanto a intensidade quanto o posicionamento dos jatos e, assim, modifica o caminho de propagação das ondas planetárias. A intensidade do jato polar no Hemisfério Sul, em torno da latitude $60^{\circ} \mathrm{S}$, durante o EN de SON/2015 (Fig. 4) é similar ao do valor máximo obtido no EN de SON/2002. Já em torno da latitude $30^{\circ} \mathrm{S}$, a 
U em 300hPa

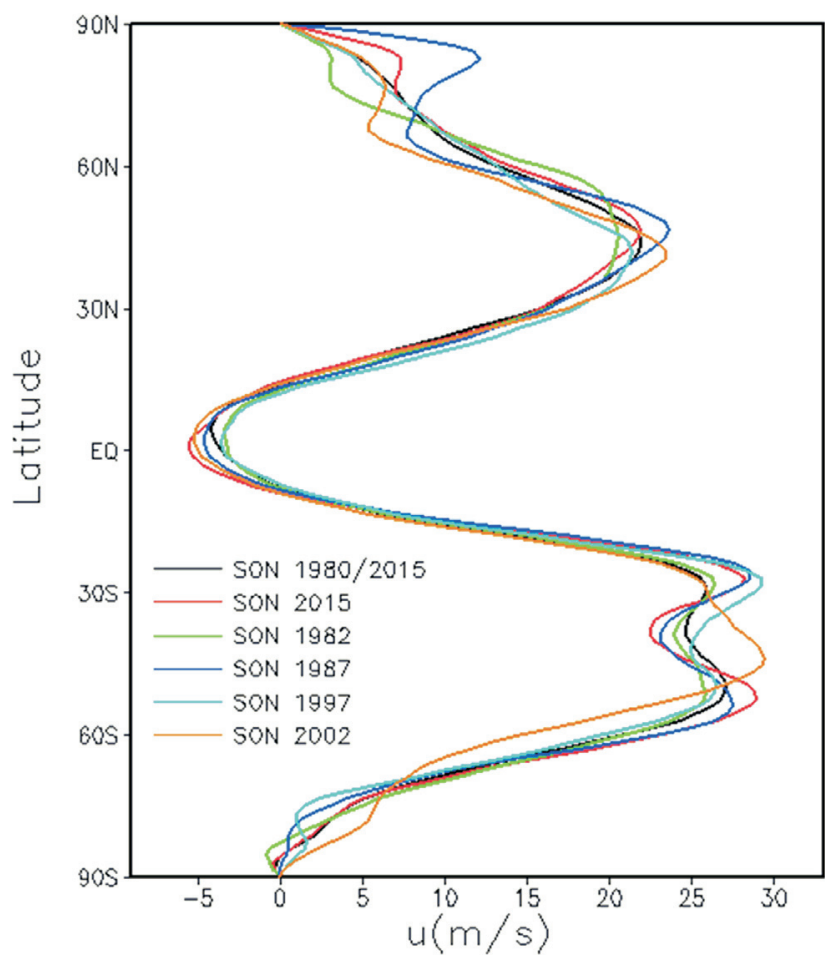

Figura 4 - Média da componente zonal do vento $(\mathrm{m} / \mathrm{s})$ por latitude no nível de $300 \mathrm{hPa}$. SON/2015 é representado pela cor vermelha e SON climatológico (1980/2015) pela cor preta.

intensidade do vento zonal no evento de 2015 só é menor do que a do evento de SON/1997.

Outra forma de avaliar a intensidade do escoamento atmosférico é através das anomalias da intensidade da componente zonal do vento (u) nos níveis de 300, 500 e $1000 \mathrm{hPa}$ em cada mês (setembro, outubro e novembro). Considerando o oceano Pacífico e a AS (Fig. 5), nota-se que os ventos de oeste (valores positivos) a cerca de $30^{\circ} \mathrm{S}$ estão mais intensos à medida que a altitude aumenta. Em setembro, em altos níveis (Fig. 5a), o núcleo mais intenso de ventos de oeste está localizado a leste da Austrália em torno de $30^{\circ} \mathrm{S}$, estendendo-se até o centro do oceano Pacífico. Essa intensidade diminui a partir de $120^{\circ}$ de longitude oeste, com anomalia positiva menos intensa que cruza a AS pelo norte do Chile, Bolívia, nordeste da Argentina, sul do Brasil, Paraguai e Uruguai. Esse mesmo padrão ocorre em baixos níveis (Figs. 5d-g), mas com valores menores de anomalia positiva. Ao sul dos ventos mais intensos em $30^{\circ} \mathrm{S}$ no oceano Pacífico, há anomalias negativas do vento zonal, indicando ventos de oeste mais fracos. Já a sul de $60^{\circ} \mathrm{S}$ os ventos tornam-se mais intensos. Em outubro (Figs. 5b-e-h), as anomalias positivas do vento zonal próximas a $30^{\circ} \mathrm{S}$ estão ligeiramente enfraquecidas no setor que cruza a AS sobre o Uruguai e Rio Grande do Sul (padrão que ocorre nos três níveis atmosféricos). Em no- vembro (Figs. 5c-f-i), os ventos de oeste em $300 \mathrm{hPa}$ a cerca de $30^{\circ} \mathrm{S}$ são mais intensos próximos da $\mathrm{AS}$, enquanto que nos meses anteriores próximo da Austrália. Nesse período, a sul de $30^{\circ} \mathrm{S}$ no oceano Pacífico, também há anomalias negativas do vento zonal indicando que a intensidade do vento decresce, voltando a aumentar a cerca de $60^{\circ} \mathrm{S}$.

De acordo com Ambrizzi e Hoskins (1997), os jatos são guias de ondas na atmosfera e como o processo de formação dos ciclones extratropicais tem, geralmente, suporte dinâmico da presença dos jatos em altitude, os mesmos afetam a ocorrência de ciclones. Reboita et al. (2014) verificaram que não há diferença significativa no número de ciclogêneses extratropicais em anos de EN, neutros e de LN, mas que há uma mudança na região preferencial de ocorrência desses sistemas. No EN de 2015, comparandose as Figs. 6a-c com as Figs. 5a-i, nota-se que há anomalias positivas na densidade da trajetória dos ciclones nas latitudes próximas de $30^{\circ} \mathrm{S}$ no oceano Pacífico em direção à AS que correspondem à região com ventos de oeste mais intensos, ou seja, há um suporte do jato para a formação dos ciclones em superfície. No oceano Atlântico, as anomalias positivas da densidade da trajetória dos ciclones são registradas em outubro e novembro. Nos três meses não há anomalias no sul da Argentina (Fig. 6), enquanto que no setor do Atlântico próximo a $60^{\circ} \mathrm{S}$ há anomalias positivas. Considerando as anomalias da densidade juntas numa mesma figura (Fig. 6d) fica mais evidente que durante a primavera austral de 2015 ocorreu maior frequência de ciclones próximo ao sudeste da AS (cores do amarelo ao laranja na Fig. 6d) e menor ao norte e sul dessa região. A região mais ciclogenética também é caracterizada por sistemas com pressão mais profunda, como indicam as anomalias de pressão no centro dos sistemas (Fig. 6e). Portanto, as anomalias positivas de precipitação registradas na primavera austral de 2015 podem ter contribuição dos ciclones extratropicais.

Em episódios de EN, como a atividade convectiva no Pacífico Tropical fica deslocada para o setor central e leste, as células de circulação de Walker também ficam deslocadas. A Fig. 7 mostra o campo de ômega que representa o movimento vertical, onde é definido como movimento ascendente os valores negativos (cores azuis) e descente os valores positivos (cores em vermelho). Em períodos sem a atuação de eventos ENOS (Fig. 7a), há movimentos ascendentes entre $60^{\circ} \mathrm{E}$ e $180^{\circ}$, subsidentes nas cercanias de $120^{\circ} \mathrm{W}$, ascendentes próximos a $60^{\circ} \mathrm{W}$ (que é a Amazônia) e subsidentes a cerca de $0^{\circ}$. Já no evento EN de 2015 (Fig. 7b), nota-se um deslocamento da região com movimentos ascendentes entre $60^{\circ} \mathrm{E}$ e $180^{\circ}$ para longitudes a leste. Com isso, o ramo descendente dessa célula também se desloca para leste, atuando de maneira que enfraquece os movimentos ascendentes próximos de $60^{\circ} \mathrm{W}$ em níveis médios e altos. Além disso, tal ramo descendente também atua sobre o nordeste do Brasil intensificando os movimentos subsidentes. Essa região de subsidência sobre a AS, 
(a)

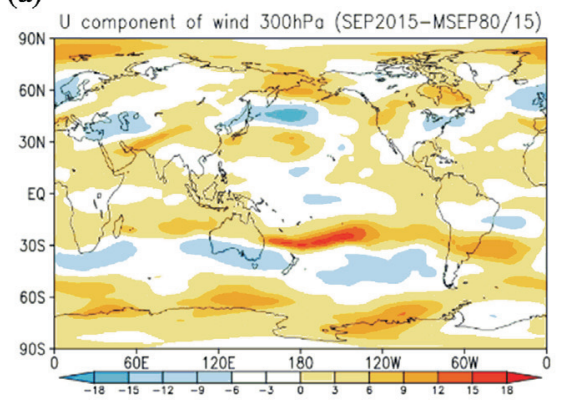

(1)

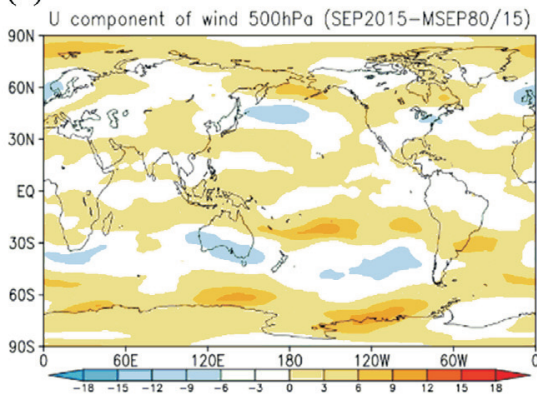

(g)

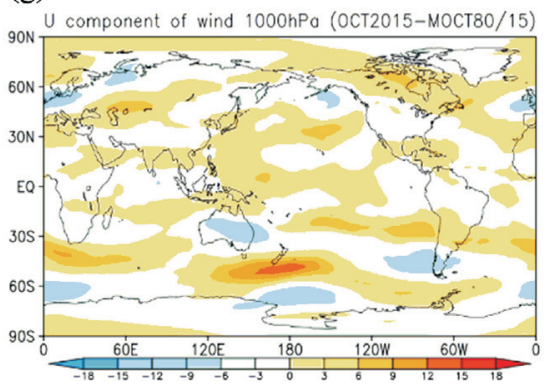

(b)

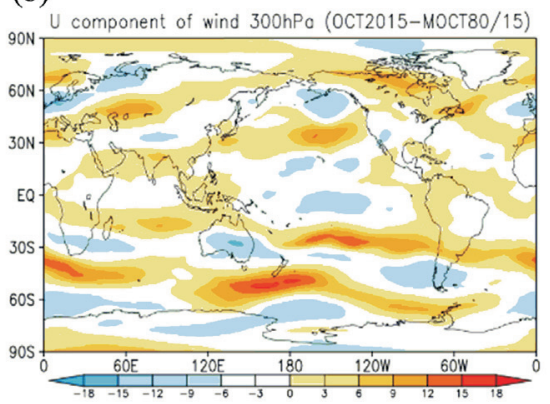

(e)

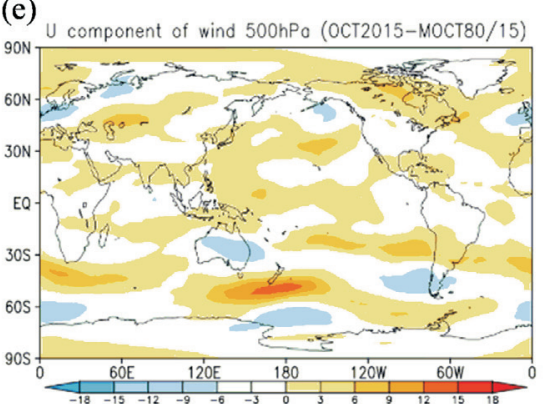

(h)

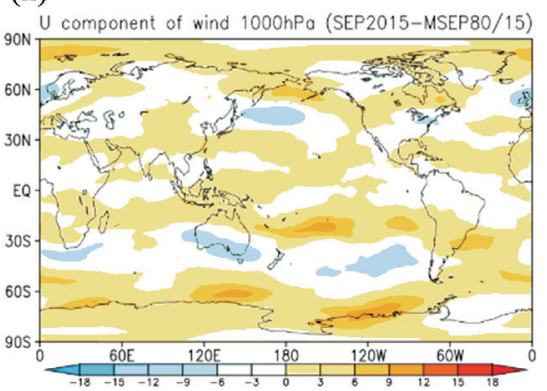

(c)

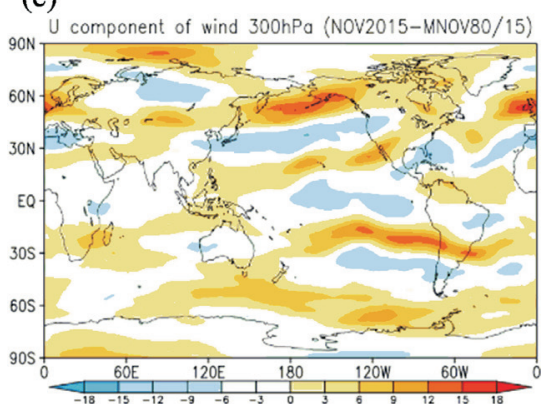

(f)

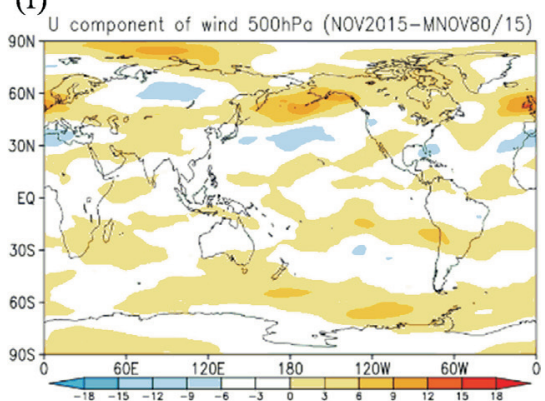

(i)

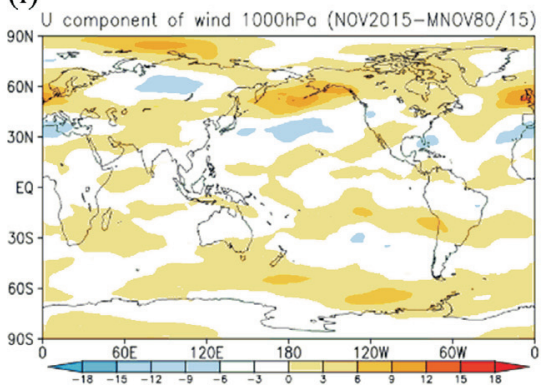

Figura 5 - Anomalia da componente zonal do vento $\left(\mathrm{m} \mathrm{s}^{-1}\right)$ em (a-c) $300 \mathrm{hPa}$, (d-f) $500 \mathrm{hPa}$ e (h-i) $1000 \mathrm{hPa}$ para os meses de SON, baseado nos dados da reanálise ERA-Interim.

tanto na climatologia quanto no evento de 2015 é fragmentada por uma região de movimentos ascendentes a cerca de $80^{\circ} \mathrm{W}$; sugere-se que esses movimentos ascendentes estejam mais relacionados com a topografia andina, do que com a estrutura térmica da atmosfera. Na Fig. 7c têm-se as anomalias do movimento vertical. Destaca-se, que sobre a Amazônia, os movimentos ascendentes em baixos níveis não são suprimidos; a precipitação é reduzida devido à influência da subsidência que passa a existir em médios e altos níveis.

Alteração nas regiões com intensos movimentos ascendentes e subsidentes na atmosfera (Fig. 7) implica em alteração no padrão das ondas na atmosfera (Fig. 8), uma vez que não somente a circulação longitudinal dos ventos é afetada (Célula de Walker), mas também a circulação meridional (Célula de Hadley) e, desta forma, o posicionamento dos guias de ondas (conforme a Fig. 4 discutida anteriormente). As alterações podem ser observadas no campo de anomalias de altura geopotencial em diferentes níveis da atmosfera (Fig. 8), sendo que as anomalias posi- tivas indicam maiores alturas (maiores pressões), e causam a inibição de convecção. Já as anomalias negativas, indicam o contrário. Nos três meses analisados e em todos os níveis verticais, há um padrão de onda que se propaga do sul da Austrália em direção à AS. Esse padrão de onda inicia com um centro de anomalia positiva de altura geopotencial ao sul da Austrália (Fig. 8). Em setembro, em $500 \mathrm{hPa}$ (Fig. 8d) aparece um centro positivo a oeste do sul da AS e outro positivo entre o sul da AS e o oceano Atlântico e esse padrão também é registrado em $1000 \mathrm{hPa}$ (Fig. 8g). Em outubro, o padrão de onda apresenta algumas diferenças nas posições dos centros de anomalias comparadas às de setembro (Figs. 8b-e-h). Agora no sul da AS há anomalia negativa e do extremo sul ao oceano, anomalia positiva. Isso ocorre nos três níveis atmosféricos em análise, indicando uma atmosfera barotrópica. O padrão das anomalias no mês de novembro se assemelha mais com o de outubro. Nos três meses analisados, predominaram anomalias negativas de altura geopotencial em superfície no sul e sudeste da AS. Essas anomalias têm uma contribuição 

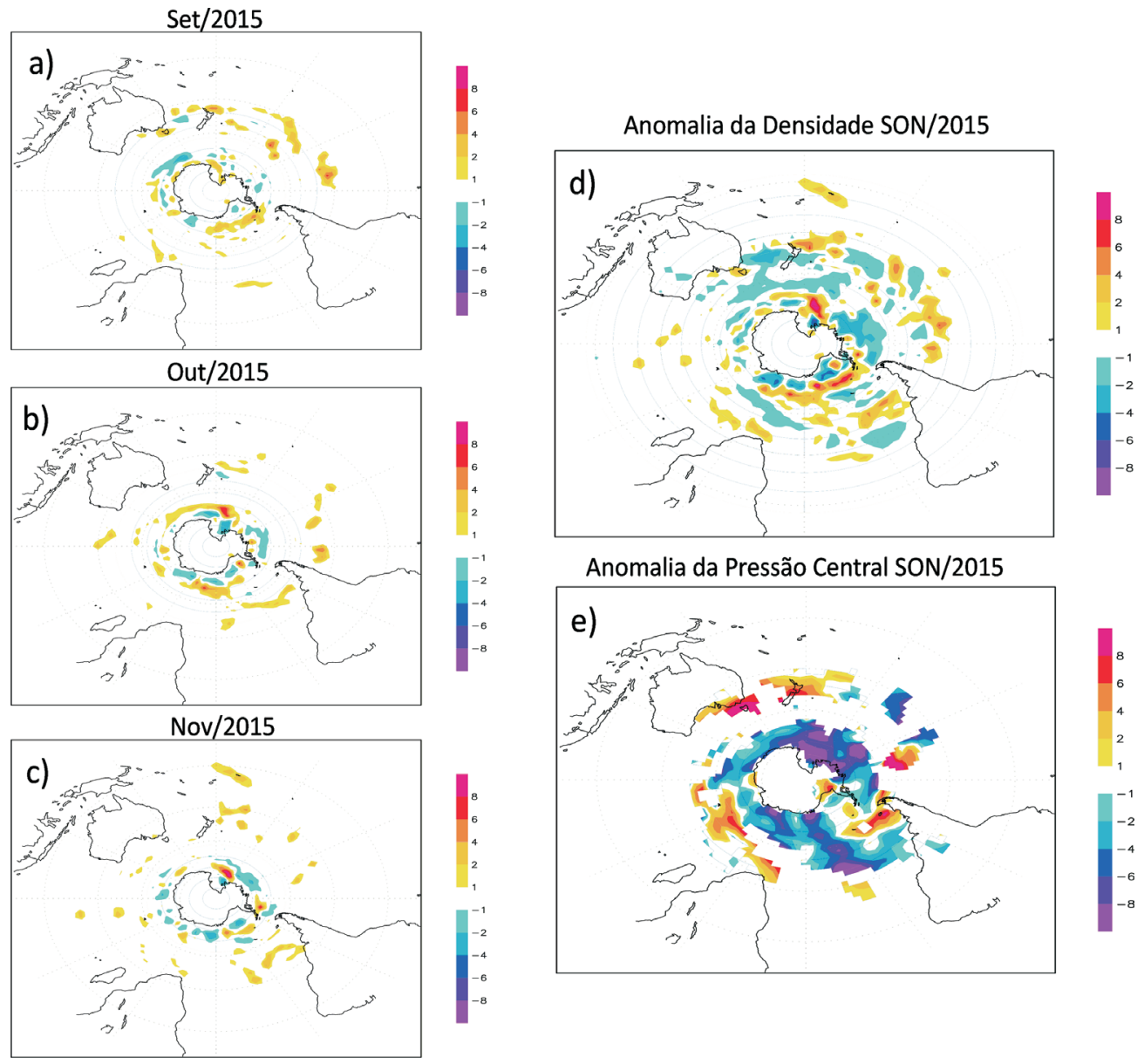

Figura 6 - Anomalia da densidade da trajetória de ciclones $\left(10^{-3} \text { ciclones / (graus de latitude) }\right)^{2}$ em: (a) setembro, (b) outubro, (c) novembro e (d) na primavera (SON) de 2015. Já (e) mostra a anomalia da pressão no centro dos ciclones (hPa). A climatologia usada para cálculo das anomalias inclui os anos de 1980 a 2012.
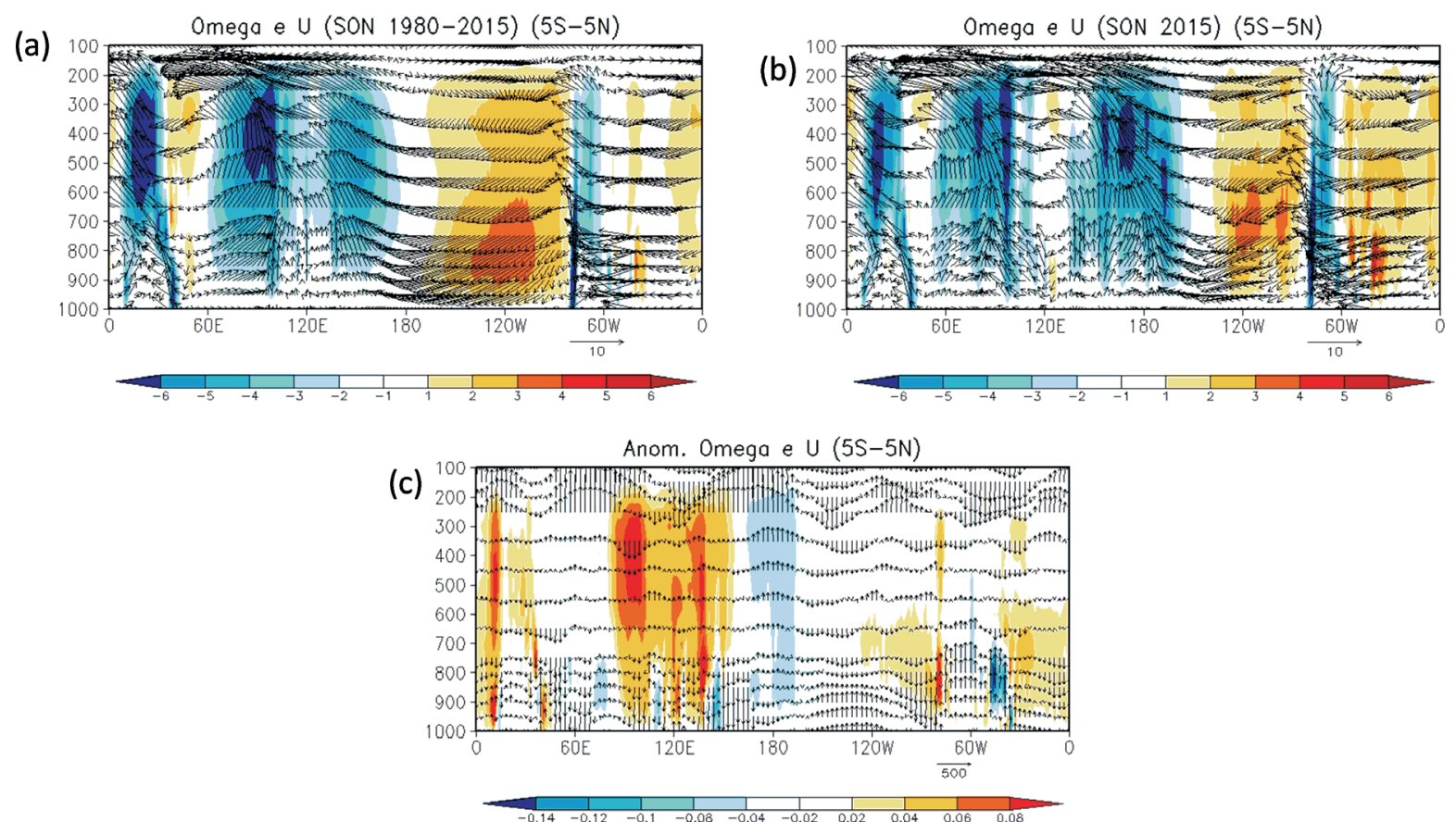

Figura 7 - Perfil vertical com a média de ômega (Pa/s) e da circulação vertical (vento zonal e ômega; $\mathrm{m} / \mathrm{s}$ ) entre $10^{\circ} \mathrm{S}$ a $10^{\circ} \mathrm{N}$ para (a) SON de 1980 a 2015 (b) SON/2015 e (c) anomalia. 
(a)

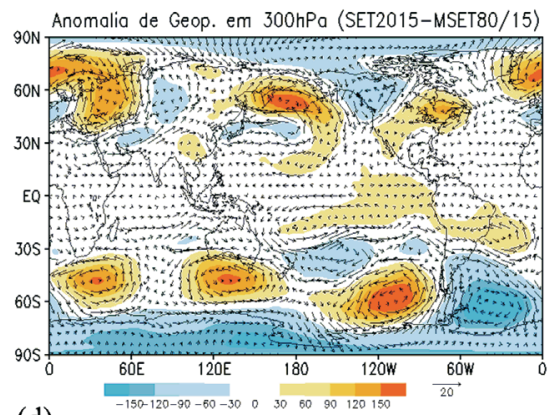

(d)

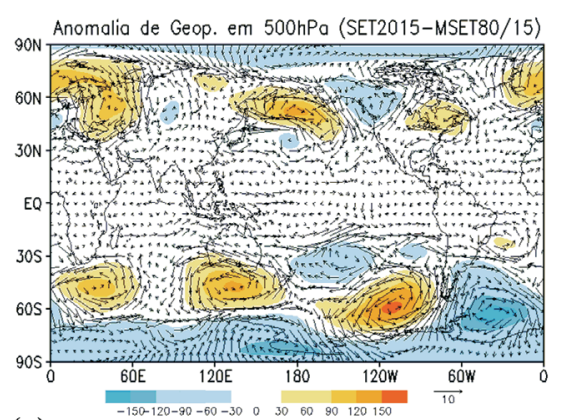

(g)

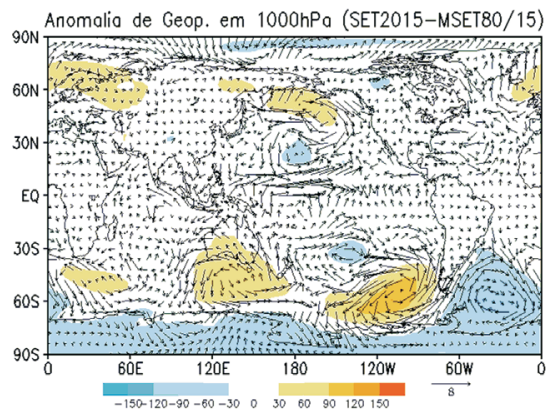

(b)

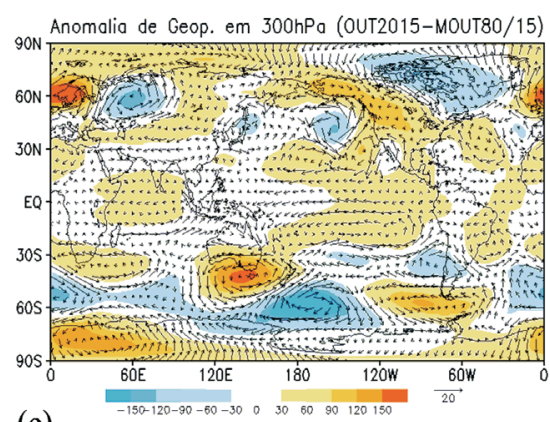

(e)

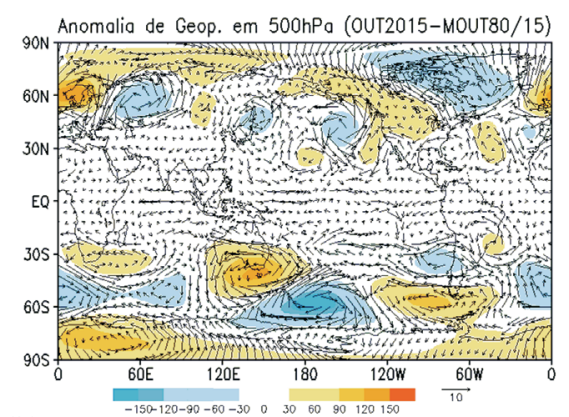

(h)

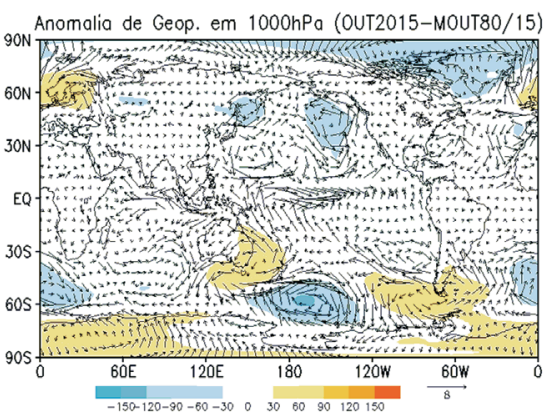

(c)

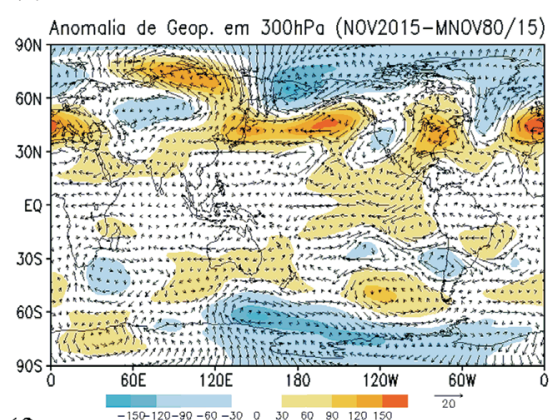

(f)

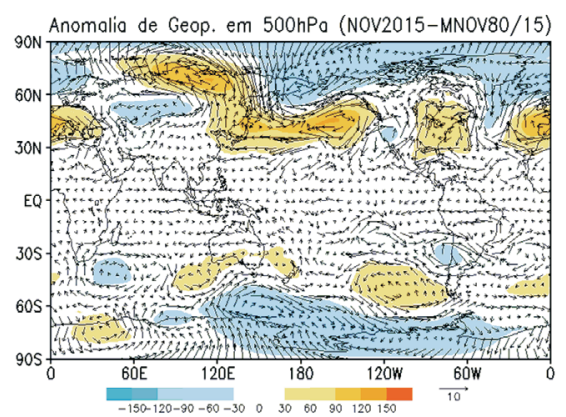

(i)

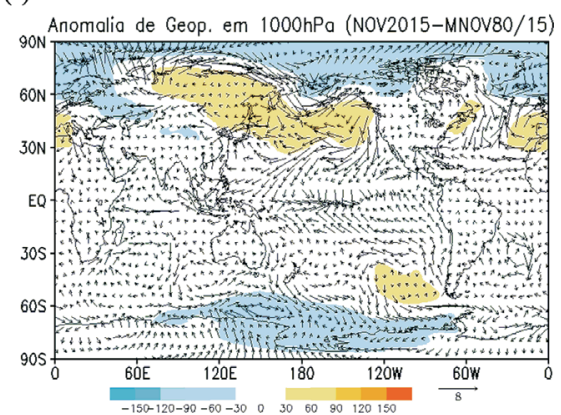

Figura 8 - Anomalia de altura geopotencial (m) e da direção do vento (setas) em (a-c) 300 hPa, (d-f) 500 hPa e (h-i) 1000 hPa para os meses de SON/2015, aseado nos dados da reanálise ERA-Interim.

importante para tais regiões, pois elas ajudam a modular a trajetória do JBN para o sudeste da AS (Campetella e Vera, 2002). Uma vez que esse jato transporta umidade dos trópicos para os subtrópicos, contribuirá para a precipitação no sudeste da AS. A fim de mostrar que nos eventos de EN pode ocorrer maior convergência do fluxo de umidade no sudeste da AS foi elaborada a Fig. 9.

A Fig. 9 mostra a anomalia da divergência do fluxo de umidade integrado na vertical (1000-100 hPa). Na figura, os valores negativos indicam convergência do fluxo de umidade, enquanto que os valores positivos indicam divergência do fluxo. No sudeste da AS, em torno de $30^{\circ} \mathrm{S}$, há convergência do fluxo de umidade, o que também contribui para a precipitação.

\subsection{Anomalias de precipitação}

Todas as alterações mencionadas na atmosfera no período de SON/2015 comparadas à climatologia implicam em modificações na precipitação e temperatura do ar sobre a AS. A magnitude dessas alterações depende intrinsecamente da magnitude do aquecimento anômalo das águas do oceano Pacífico Tropical central e leste. De acordo com o ONI, o EN 2015/2016 é considerado um evento muito forte. Para mostrar os impactos do EN de SON/2015 na precipitação construíram-se três figuras de anomalias (Fig. 10): uma de SON/2015 em relação à composição dos eventos EN clássicos ocorridos desde 1980 que foram os de 1982 e 1997; outra de SON/2015 em relação à climatologia de 1980/2015 e, por fim, SON dos episódios EN selecionados (1982 e 1997) em relação à climatologia de 1980/2015.

$\mathrm{O}$ evento de SON/2015 comparado à climatologia (Fig. 10d) mostra anomalias negativas de precipitação na região centro-norte da $\mathrm{AS}$ e anomalias positivas no sudeste da AS que se estendem em direção ao oceano Atlântico. Esse padrão de anomalias é diferente daquele em que é computada a média da precipitação em SON de 1982 e 1997 e realizada a diferença em relação à climatologia (Fig. 10f), pois o evento de SON/2015 mostra déficit mais 


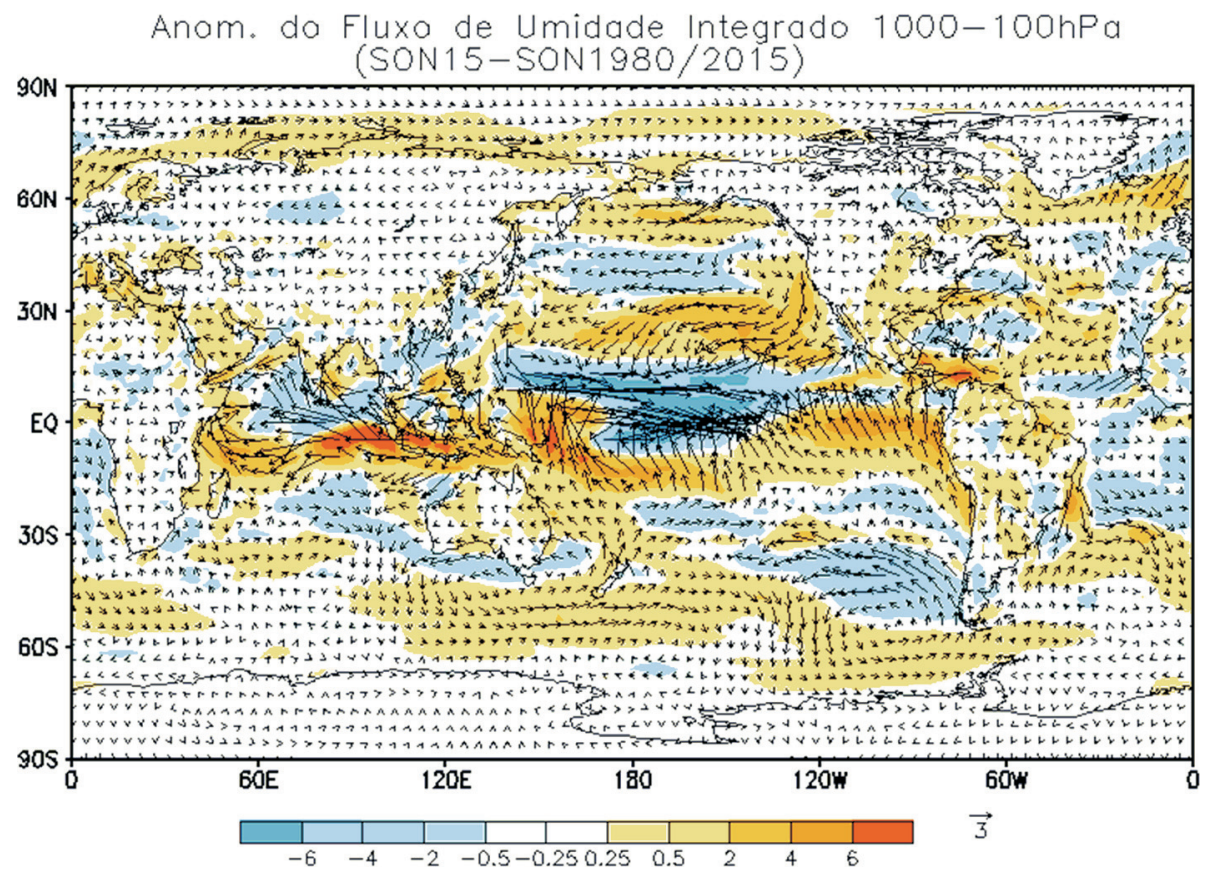

Figura 9 - Anomalia da divergência do fluxo de umidade integrado 1000-100 hPa no período de SON/2015. O tamanho dos vetores indica a magnitude do fluxo de umidade em $\mathrm{kg}(\mathrm{m} . \mathrm{s})^{-1}$.

acentuado de precipitação na AS enquanto nos outros dois eventos, as anomalias negativas se restringem ao extremo norte do continente e litoral do nordeste do Brasil. Além disso, nos eventos de 1982 e 1997, as anomalias positivas de precipitação se estendem numa banda entre o oeste da Amazônia ao sudeste da AS. Por fim, quando a diferença entre o evento de 2015 e a média dos de 1982 e 1997 é computada, torna-se bem evidente o grande déficit de precipitação na AS durante esse evento.

O fenômeno EN é frequentemente apontado em vários estudos como causador de secas na região nordeste do Brasil e de chuvas acima da média climatológica no sul do país (Ropelewki e Halpert, 1987; Rao e Hada, 1990; Grimm et al., 1996). Foley et al. (2002) também mencionam que episódios de EN tornam a Amazônia mais seca e quente do que a média climatológica. A diminuição da precipitação na Amazônia é preocupante, porque pode aumentar os riscos de incêndios sobre esta área. Por exemplo, em 1988 a seca prolongada induzida pelo EN, favoreceu muitos incêndios nesta floresta. As chamas foram extintas pela chuva somente após meses de seca, resultando em cerca de 3,3 milhões de hectares carbonizados, dos quais 1 milhão eram cobertos pela floresta tropical (Nepstad et al., 1999; Cabral et al., 2013). No episódio em estudo (2015), segundo o Instituto Nacional de Pesquisas, em setembro ocorreu um recorde de queimadas e incêndios florestais no Estado do Amazonas. Foram detectados 5.882 focos de fogo no Estado, 95\% a mais em relação a todo o mês de setembro do ano anterior. Foi considerado o maior número de incêndios em 17 anos de monitoramento realizado pelo INPE no Amazonas.
No sul do Brasil, os impactos do EN também não são positivos, pois é apontado como a principal razão para o aumento das inundações, causando perdas materiais e humanas, interrupção das atividades econômicas na área de inundação, perdas na agricultura e na contaminação da água (Tucci, 2003; Salini, 2011). Em SON/2015, a anomalia de precipitação atingiu cerca de $6 \mathrm{~mm} /$ dia acima da média climatológica na região sul do Brasil, enquanto anomalias negativas de mesma magnitude atingiram a Amazônia e o nordeste do Brasil (Fig. 10d).

Enquanto, a redução da precipitação no nordeste do Brasil está associada com os movimentos descentes da célula de Walker (Fig. 7c), no sudeste da AS, o excesso de precipitação está associado com anomalias negativas de altura geopotencial sobre parte do sudeste da AS (Fig. 8) favorecendo o deslocamento do JBN para tal região (Fig. 9), que transporta umidade dos trópicos para os subtrópicos. Além disso, o suprimento de umidade e a corrente de jato subtropical podem favorecer as anomalias positivas da trajetória de ciclones no oceano Atlântico, próximo ao sudeste da AS, e esses sistemas podem contribuir para os maiores totais de precipitação (Silva et al., 2010). Outro fator que deve ser levado em consideração, é que nas anomalias de altura geopotencial, em geral, há um centro de anomalia positiva a oeste do sul da AS. Isso pode configurar uma situação de bloqueio atmosférico e como os sistemas transientes desviam dessa região, acabam passando sobre o norte da Argentina, sul do Brasil e Uruguai e, portanto, favorecendo a chuva. Oliveira et al. (2013) sugerem que em anos de EN há maior frequência de bloqueios atmosféricos no setor referido. Em geral, os padrões atmos- 
féricos descritos no evento EN de SON/2015, classificado como MIX, se assemelham ao estudo climatológico de Andreoli et al. (2016). Nesse, para o evento tipo MIX, os

(a)

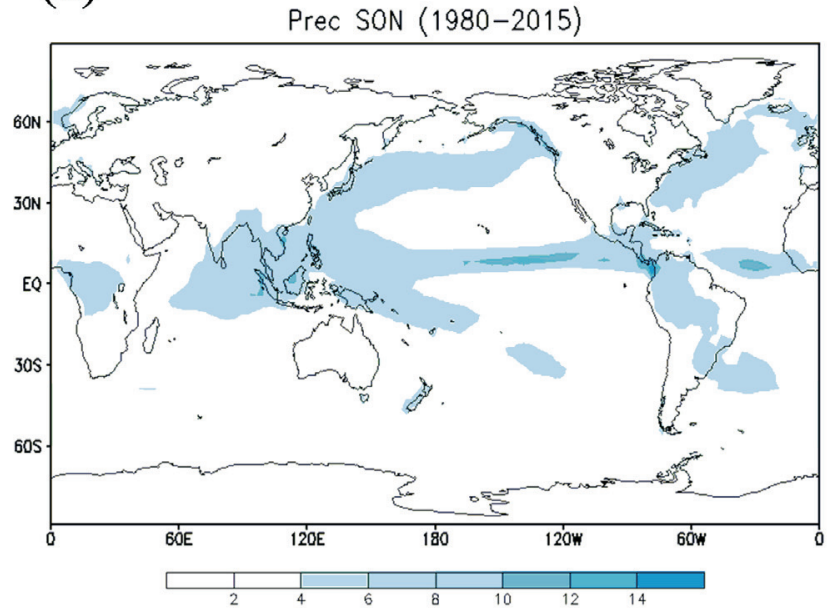

(c)

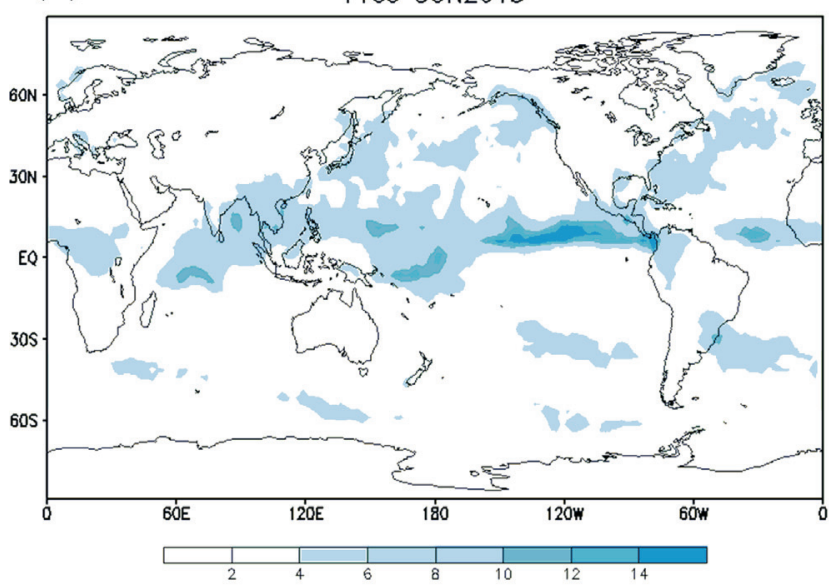

(e)

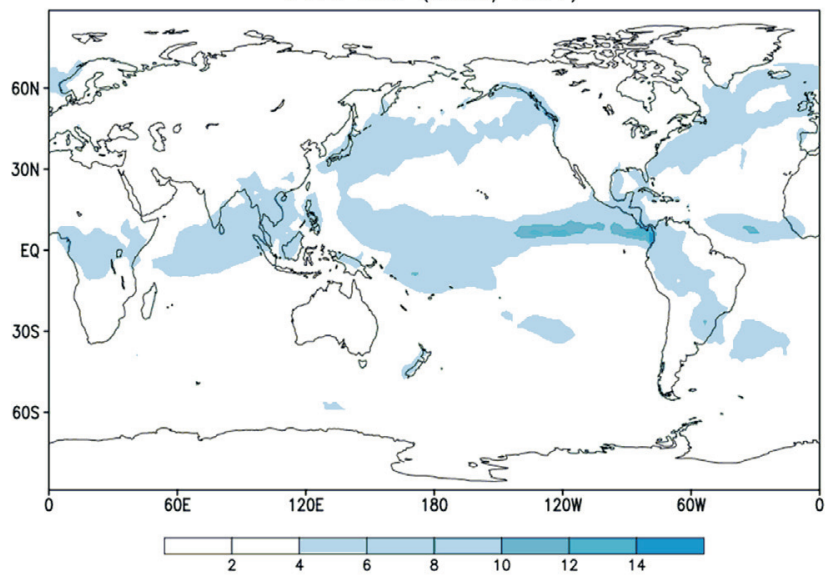

autores mencionam que o padrão do trem de ondas de Rossby é muito similar ao PSA1 com uma anomalia ciclônica sobre o sudeste da AS e arredores, o que favorecerá as

(b)

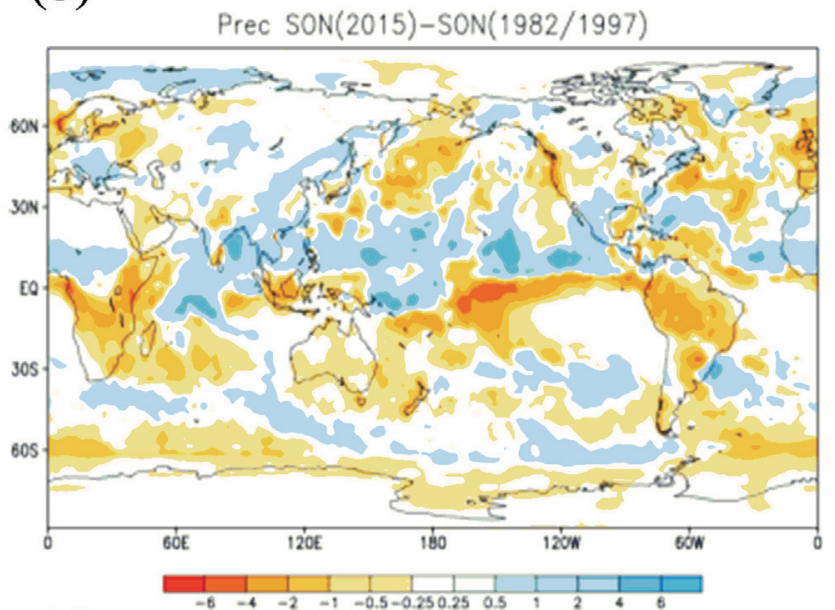

(d)

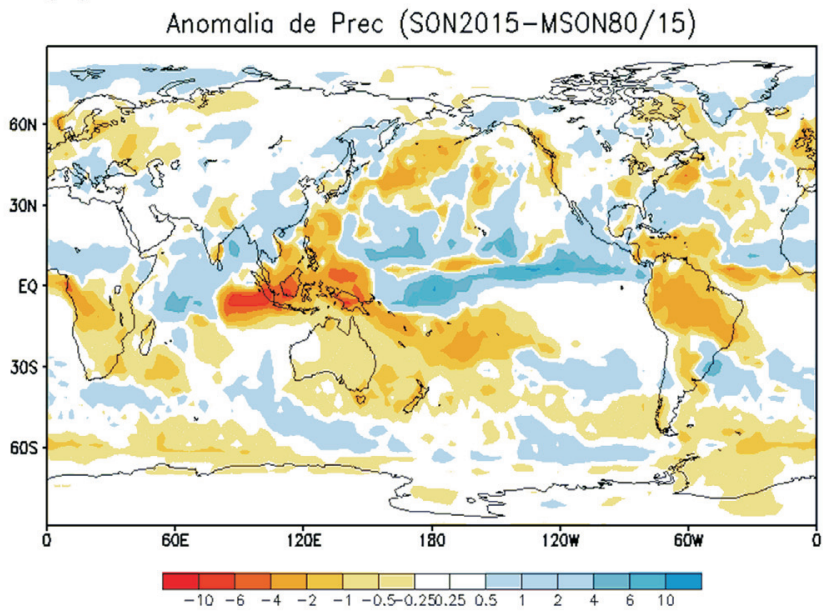

(f)

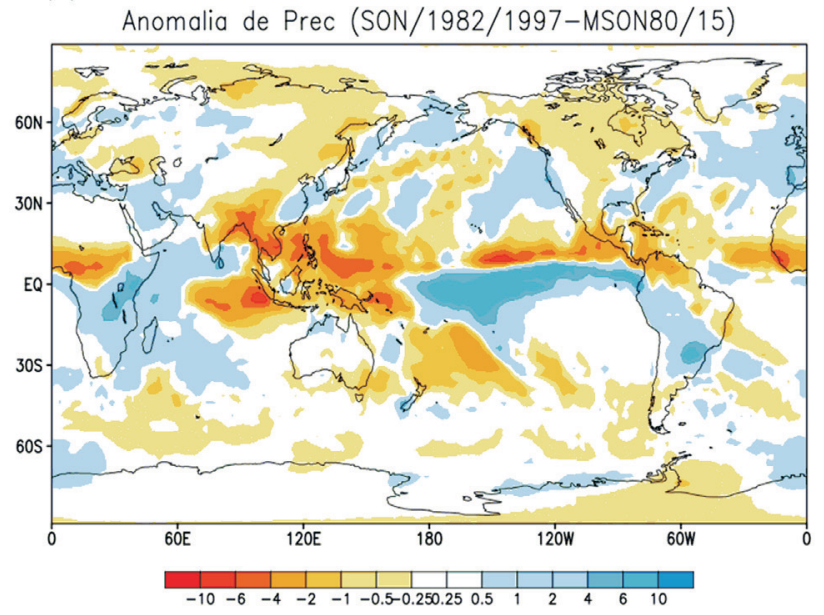

Figura 10 - Precipitação (mm/dia): (a) média climatológica (1980/2015) de SON, (b) anomalia de SON/2015 em relação a SON dos eventos EN selecionados (c) média SON/2015, (d) anomalia SON/2015 em relação a SON climatológico, (e) média SON dos eventos EN selecionados (f) anomalia de SON dos EN selecionados em relação a SON climatológico. 
anomalias positivas de precipitação. Já a circulação anômala de Walker intensifica e mostra movimentos subsidentes sobre a AS equatorial entre $70^{\circ}$ a $50^{\circ} \mathrm{W}$, o que contribui para as condições secas.

Por fim, pode-se relacionar o padrão espacial da precipitação (Fig. 10) com as anomalias da temperatura do ar (Fig. 2c). As regiões com déficit (excesso) de precipitação são caracterizadas por anomalias positivas (negativas) de temperatura do ar. Fato que está associado à energia nos processos de evaporação e condensação.

\section{Conclusões}

O EN 2015/2016 é considerado um evento muito forte com base no índice ONI e também é classificado como tipo MIX devido às características espaciais e temporais das anomalias de TSM no oceano Pacífico Tropical. O presente estudo teve como objetivo documentar as carac- terísticas da atmosfera no período de SON/2015. As anomalias negativas na precipitação sobre a AS (Amazônia, nordeste e centro-oeste do Brasil) foram mais intensas que nos episódios clássicos de EN de 1982 e 1997. Já as anomalias positivas se restringiram a uma menor área do sudeste da AS em SON/2015, comparadas aos dos dois outros eventos. Pode-se sugerir que as anomalias de precipitação na AS em SON/2015 estão relacionadas com: anomalias positivas de TSM no oceano Pacífico Tropical central e leste, que favorecem uma intensificação do gradiente horizontal de temperatura do ar entre os trópicos e subtrópicos do oceano Pacífico Sul e, desta forma, auxilia a intensificação do jato subtropical. O jato, juntamente com as anomalias negativas de altura geopotencial (em toda a troposfera) sobre o sul da AS e oceano Atlântico, pode ajudar a ciclogênese na costa sudeste da AS. Esta, por sua vez, também pode contribuir para canalizar o jato de baixos níveis a leste dos Andes, que transporta umidade dos tró-
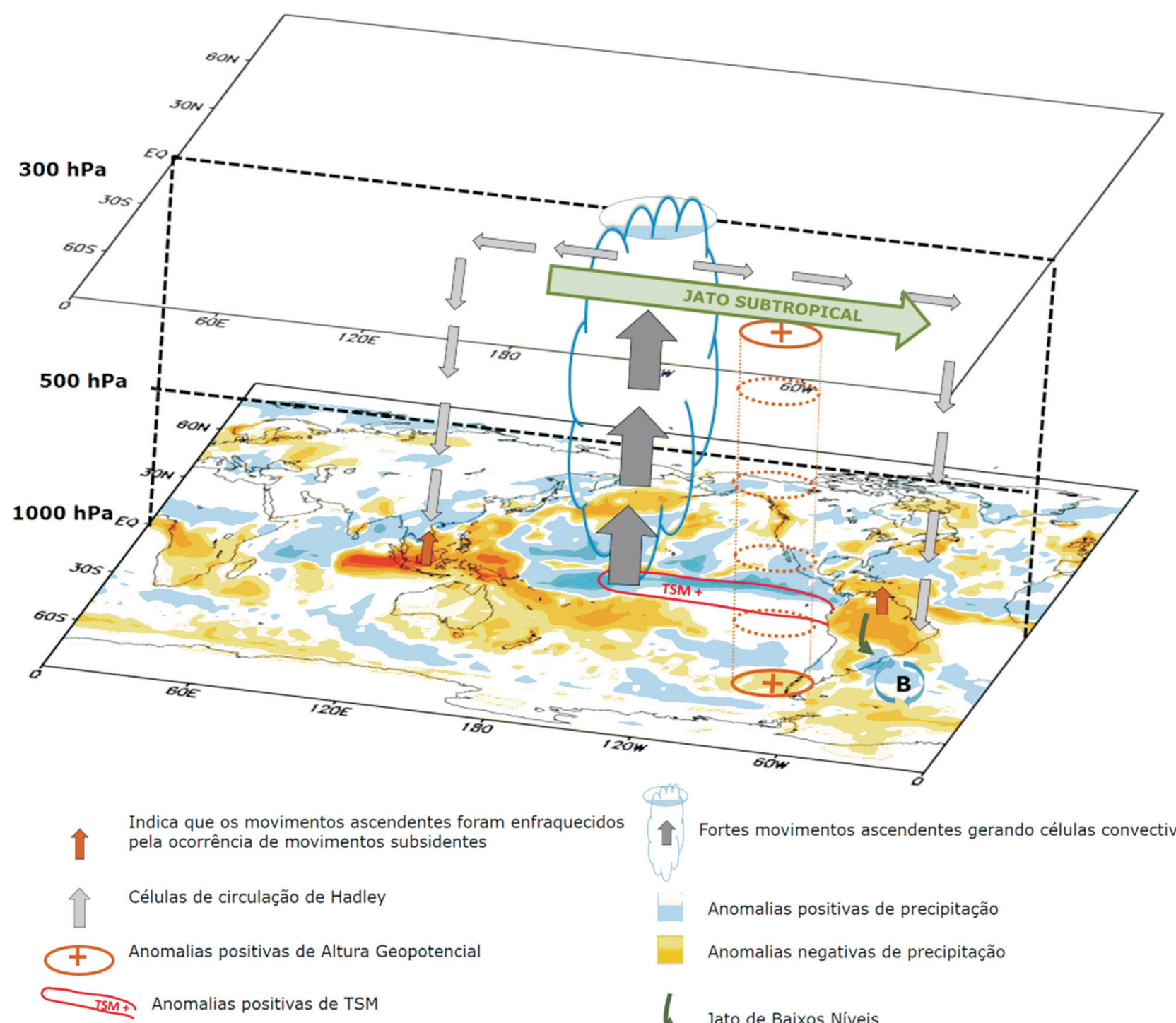

Fortes movimentos ascendentes gerando células convectivas

Anomalias positivas de precipitação

Anomalias negativas de precipitação

Jato de Baixos Níveis

Figura 11 - Impactos do EN 2015 na circulação geral da atmosfera durante os meses de SON/2015. 
picos para os subtrópicos. Além disso, no oceano Pacífico próximo ao sul da AS, há uma anomalia positiva de altura geopotencial que atua bloqueando a passagem dos sistemas transientes e que acabam adquirindo uma trajetória meridional e acompanhando o deslocamento zonal dos jatos. Essas características são importantes para as anomalias positivas de precipitação no sudeste da AS. Já o deslocamento da célula de Walker para leste em anos de EN contribui para o enfraquecimento dos movimentos ascendentes em médios e altos níveis nas latitudes tropicais a cerca de $60^{\circ} \mathrm{W}$ e aumento dos movimentos subsidentes so bre o nordeste do Brasil, o que leva à redução de precipitação nessa região. A Fig. 11 esquematiza as características descritas.

\section{Referencias}

ACEITUNO, P. On the functioning of the southern oscillation in the South America sector - Part I: surface climate. Monthly Weather Review, v. 116, n. 3, p. 505-524, 1988.

ACEITUNO, P. On the functioning of the southern oscillation in the South America sector - Part II: Upper-Air Circulation. Journal of Climate, v. 21, p. 341-355, 1989.

ADLER, R.F.; HUFFMAN, G.J.; CHANG, A.; FERRARO, R.; XIE, P. et al. The version 2 Global Precipitation Climatology Project (GPCP) monthly precipitation analysis (1979-present). Journal of Hydrometeorology, v. 4, n. 6, p. 1147-1167, 2003.

AMBRIZZI T.; HOSKINS B. J. Stationary Rossby wave propagation in a baroclinic atmosphere. Quarterly Journal of the Royal Meteorological Society, v. 123, p. 919-928, 1997.

AMBRIZZI, T.; SOUZA, E. B.; PULWARTY, R S. The Hadley and Walker regional circulations and associated ENSO impacts on the South American Seasonal Rainfall. In: Henry F. Diaz; Raymond S. Bradley. (Org.). The Hadley Circulation: Present, Past and Future. 1 ed. Netherlands: Kluwer Academic Publishers, v. 21, p. 203-235, 2004.

ANDREOLI, R.V.; OLIVEIRA, S.S.; KAYANO, M.T.; VIEGAS, J.; SOUZA, R.A.F.; CANDIDO, L.A. The influence of different El Niño types on the South American rainfall. International Journal of Climatology, v. 37, p. 13741390, 2016.

ARAVÉQUIA, J.A.; DIAS, P.L.S. Ferramenta de análise e prognóstico de anomalias climáticas usando funções de Green de um modelo barotrópico divergente. In: Anais do XIII Congresso Brasileiro de Meteorologia. Fortaleza. 2004. Disponível

em http://urlib.net/cptec.inpe.br/walmeida/2004/09.16.14.46, acesso em novembro, 2016.

ASHOK, K.; BEHERA, W.; RAO, S.A.; YAMAGATA, T. El Niño Modoki and its possible teleconnection. Journal of Geophysical Research, v. 112, p. C11007, 2007.

BARNETT, T.P. Variations in near-global sea level pressure. Journal of the Atmospheric Sciences, v. 42, p. 478-501, 1985.

BJERKNES, J.A. Possible response of the atmosphere Hadley circulation to equatorial anomalies of ocean temperature. Tellus, v. 18, n. 4, p. 820-829, 1966.

CABRAL, A.L.A.; MORAS FILHO, L.O.; BORGES, L.A.C. Uso do fogo na agricultura: legislação, impactos ambientais e realidade na Amazônia. Fórum Ambiental da Alta Paulista, v. 9, n.5, 2013

CAMPETELLA, C.M.; VERA, C.S. The influence of the Andes Mountains on the South American low-level flow. Geophysical Research Letters, Wiley Online Library, v. 29, n. 17, p. $7-1,2002$.

CAPOTONDI, A.; WITTENBERG, A.T.; NEWMAN, M.; DI LORENZO, E.; YU, J.; BRACONNOT, P.; COLE, J.; DEWITTE, B. et al. Understanding ENSO diversity, Bulletin of the American Meteorological Society, v. 96, p. 921-938, 2015.

CHEN, B.; SMITH, S.R.; BROMVICH, D.H. Evolution of the Tropospheric Split Jet over the South Pacific Ocean during the 1986-89 ENSO Cycle. Montly Weather Review, v. 124 , p. 1711-1731, 1996

COELHO, C.A.S.; DRUMOND, A.R.M.; AMBRIZZI, T. Estudo climatológico sazonal da precipitação sobre o Brasil em episódios extremos da Oscilação Sul. Revista Brasileira de Meteorologia, v.14, n.1, p.49-65, 1999.

COELHO C.A.S. Anomalias de precipitação sobre a América do Sul e sua relação com a Temperatura da Superfície do Mar dos oceanos Pacífico e Atlântico durante períodos de extremos de El Niño-Oscilação Sul. Dissertação de Mestrado em Meteorologia. Universidade de São Paulo, 2001.

DEE, D.P.; UPPALA, S.M.; SIMMONS, A.J.; BERRISFORD, P.; POLI, P.; KOBAYASHI, S. et al. The ERA-Interim reanalysis: Configuration and performance of the data assimilation system. Quarterly Journal of the Royal Meteorological Society, v. 137, p. 553-597, 2011.

FOLEY, J.A.; BOTTA, A.; COE., M.T.; COSTA, M.H. El NinoSouthern oscillation and the climate, ecosystems and rivers of Amazonia, Global Biogeochemical Cycle, v. 16, p. 1-17, 2002.

GRIMM, A.M.; FERRAZ, S.E.T.; GOMES, J. Precipitation anomalies in southern Brazil associated with El Niño and La Niña events. Journal of Climate, v. 11, p. 2863-2880, 1998.

GRIMM, A.M.; AMBRIZZI, T. Teleconnections into South America from the tropics and extratropics on interannual and intraseasonal timescales. Past Climate Variability in South America and Surrounding Regions. From the Last Glacial Maximum to the Holocene. Springer, v. 14, p 159-191, 2009

GRIMM, A.M.; SILVA DIAS, P. L. Analysis of tropical-extratropical interactions with influence functions of a barotropic model. Journal of the Atmospheric Sciences, v. 52, p. 3538-3555, 1995.

GRIMM, A.M.; TELEGINSKI, E.D.; FREITAS, S.M.; COSTA, S.; FERLIZI, P.G.; GOMES, J. Anais do Congresso Brasileiro de Meteorologia, Campos do Jordão, v. 2, p. 11131117, 1996.

GRIMM, A.M.; FERRAZ S.E.T.; GOMES, J. Dynamical aspects of the Southern Brazil rainfall - El Niño relationship. Fifth International Conference on Southern Hemisphere Meteorology and Oceanography, v. 1, p. 322-323, 1997.

GRIMM, A.M.; FERRAZ, S.E.T; CARDOSO, A. de O. Influência de El Niño sobre a chuva no Nordeste Brasileiro. X Congresso Brasileiro de Meteorologia e VII Congresso da FLISMET, Brasília, 1998a.

GRIMM, A.M.; FERRAZ, S.E.T.; GOMES, J. Precipitation anomalies in southern Brazil associated with El Niño and La 
Niña events. Journal of Climate, v. 11, p. 2863-2880, 1998b.

GRIMM, A.M.; BARROS, V.R.; DOYLE, M.E. Climate variability in southern South America associated with El Niño and La Niña events.Journal of Climate, v. 13, p. 35-58, 2000.

GRIMM, A.M.; PAL, J.S.; GIORGI, F. Connection between Spring Conditions and Peak Summer Monsoon Rainfall in South America: Role of Soil Moisture, Surface Temperature, and Topography in Eastern Brazil. Journal of Climate, v. 20, p. 5929-5945, 2007.

HOREL, J.D.; WALLACE, J.M. Planetary scale atmospheric phenomena associated with the Southern Oscillation. Monthly Weather Review, v. 109, p. 813-829, 1981.

HOLTON, J.R. Introduction to Dynamic Meteorology. Elsevier Academic Press, New York, $4^{\text {th }}$ Edition, 535 pp, 2004.

HOSKINS, B.J.; KAROLY, D.J. The Steady linear response of a spherical atmosphere to thermal and orographic forcing. Journal of the Atmospheric Sciences, v. 38, p. 1179-1196, 1981.

INSTITUTO NACIONAL DE PESQUISAS ESPACIAIS (INPE). Programa de Queimadas - Monitoramento por Satélites. Disponível https:/queimadas.dgi.inpe.br/queimadas. Acesso em novembro, 2016.

KALNAY, E.; KANAMITSU, M.; KISTLER, W.; COLLINS, W.; DEAVEN, S. et al. The NCEP/NCAR 40-Year Reanalysis Project. Bulletin of the American Meteorology Society, v. 77, p. 437-471, 1996.

KAYANO, M.T.; ANDREOLI, R.V.; SOUZA, R.A.F.; GARCIA, S.R.; CALHEIROS, A.J. El Niño e La Niña dos últimos 30 anos: diferentes tipos. Revista Climanalise. Edição Comemorativa de 30 anos, novembro, 2016.

KILADIS, G.N.; WEICKMANN, K.M. Circulations anomalies associated with tropical convection during northern winter. Monthly Weather Review, v. 120, p. 1900-1923, 1992.

KOUSKY, V.E.; KAYANO, M.T.; CAVALCANTI, I.F.A. A review of the southern oscillation oceanic atmospheric circulation changes and related rainfall anomalies. Tellus, v. 36, p. 490-504, 1984.

LAU, W.M. Walker Circulation. In Holton JR, Curry JA and Pyle JA (eds) Encyclopedia of atmospheric sciences. San Diego: Academic Press, p. 2505-2510, 2003.

L'HEUREUX, M.; TAKAHASHI, K.; WATKINS, A.B.; BARNSTON, A.G.; BECKER, E.J. et al. Observing and Predicting the 2015-16 El Niño. Bulletin American Meteorological Society, v. 98, doi: 10.1175/BAMS-D-16-0009.1, 2015.

MAGAÑA, V.; AMBRIZZI, T. Dynamics of Subtropical Vertical Motions over the Americas during El Niño Boreal Winters. Atmosfera, v. 18, n. 4, p. 211-233, 2005.

MANTUA, N.J. et al. A Pacific Decadal Interdecadal Climate Oscillation with impacts on Salmon production, Bulletin of American Meteorological Society, v. 78, p. 1069-1079, 1997.

MO, K.C.; WHITE, G.H. Teleconnections in the southern hemisphere. Monthly Weather Review, v. 113, n. 1, p. 22-37, 1985.

MO, K.C. Relationships between interdecadal variability in the Southern Hemisphere and sea surface temperature anomalies. Journal of Climate, v. 13, p. 3599-3610, 2000.
MO, K. C.; PAEGLE, J. N. The Pacific-South American modes and their downstream effects. International Journal of Climatology, v. 21, n. 10, p. 1211-1229, 2001.

NEPSTAD, D.C.; MOREIRA, A.G.; ALENCAR, A.A. Floresta em Chamas: Origens, Impactos e Prevenção do Fogo na Amazônia. Ipam: Brasília; 1999.

OLIVEIRA, G.S; SATYAMURTY, P. O El Niño de 1997/98: evolução e impactos no Brasil. X Congresso Brasileiro de Meteorologia. Campos de Jordão, 1998.

OLIVEIRA, F.N.M.; CARVALHO, L.M.V.; AMBRIZZI, T. A new climatology for Southern Hemisphere blockings in the winter and the combined effect of ENSO and SAM phases. International Journal of Climatology, v. 34, p. 1676 1692, 2013.

PHILANDER, S.G.H. El Nino, La Nina and the Southern Oscillation, Academic Press, 1990.

RAO, V.B.; HADA, K. Characteristics of rainfall over Brazil: Annual variations and connections with the Southern Oscillation. Theoretical and Applied Climatology, v. 42, p. 8190, 1990.

REBOITA, M.S.; ROCHA, R.P.; AMBRIZZI, T.; GOUVEIA, C. D. Trend and teleconnection patterns in the climatology of extratropical cyclones over the southern hemisphere. Climate Dynamics, v. 45, n. 7-8, p. 1929-1944, 2015.

REBOITA, M.; SANTOS, I. Influência de alguns padrões de teleconexão na precipitação no norte e nordeste do Brasil. Revista Brasileira de Climatologia, v. 15, p. 28-48, 2014.

ROPELEWSKI, C.H.; HALPERT, S. Global and regional scale precipitation patterns associated with the El Niño/Southern Oscillation. Montly Weather Review, v. 115, p. 16061626, 1987.

RUTLLANT, J. Alguns aspectos de la influencia climática, a nivel mundial y regional, del fenómeno El Niño. Investigaciones Pesqueras, Chile, v. 32, p. 9-17, 1985.

SALINI, M.F. A influência do fenômeno EI Niño oscilação sul enos (La Niña e EI Niño) na ocorrência de inundações do Vale do Taquari, RS. Monografia - Curso de Engenharia Ambiental. Centro Universitário Univates Lajeado, p. 57, 2011.

SILVA, G.A.M. AMBRIZZI, T.; MARENGO, J.A. Inter ENSO variability and its impact on the South American Low-Level Jet east of the Andes during the austral summer. Two case studies,Advances in Geosciences, v. 6, p. 283-286, 2006.

SILVA, A.M.; AMBRIZZI, T.; MARENGO, J.A. Observational evidences on the modulation of the South American low level jet east of the Andes according the ENSO variability. Annales Geophysicae, v. 27, p. 645-657, 2009.

SILVA, G.A.M.; AMBRIZZI, T. Summertime moisture transport over Southeastern South America and extratropical cyclones behavior during inter-El Niño events. Theoretical and Applied Climatology, v. 101, p. 303-310, 2010.

STULL, R.B. Meteorology for Scientists and Engineers. Brooks Cole Ed., 2a ed., p. 528, 2000.

TASCHETTO A.S.; ENGLAND M.H. El Niño Modoki impacts on Australian Rainfall. Journal Climate v. 22, p. 31673174, 2009.

TEDESCHI, R.G.; CAVALCANTI, I.F.A.; GRIMM, A.M. Influences of two types of ENSO on South American precipitation. International Journal of Climatology, v. 33, p. 1382-1400, 2013. 
TEDESCHI R.G.; GRIMM A.M.; CAVALCANTI, I.F.A. Influence of central and east ENSO on extreme events of precipitation in South America during austral spring and summer. International Journal of Climatology, v. 35, p. 20452064, 2015.

TREBERTH, K.E. El Niño Southern Oscillation (ENSO), Reference Module in Earth Systems and Environmental Sciences. Encyclopedia of Ocean Sciences (Second Edition), p. 228240, 2013.

TUCCI, C.E.M. Inundações e Drenagem Urbana. In: TUCCI, C.E.M., BERTONI, J.C. Inundações urbanas na América do Sul, ABRH, Editora da Universidade Federal do Rio Grande do Sul, Porto Alegre - RS, p.45-150, 2003.
VEIGA, J.A.P.; PEZZA, A.B.; AMBRIZZI, T.; RAO, V.B.; FRANCHITO, S.H. et al. The Energy Associated to the Pacific Walker Circulation and Its Relationship to ENSO. Atmospheric and Climate Sciences, v. 3, p. 627-642, 2013.

VERA, C.G.; SILVESTRI, G.; BARROS, V.; CARRIL, A. Differences in El Niño response over the Southern Hemisphere. Journal of Climate, v. 17, p. 1741-1753, 2004.

YU, J.Y.; KIM, S.T. Identifying the types of major El Niño events since 1870. International Journal of Climatology, v. 33, p. 2105-2112, 2013.

This is an Open Access article distributed under the terms of the Creative Commons Attribution Non-Commercial License which permits unrestricted non-commercial use, distribution, and reproduction in any medium provided the original work is properly cited. 